\title{
Larval morphology of Scydmaenus tarsatus and $S$. hellwigii, with notes on feeding behaviour and a review of the bibliography on the preimaginal stages of ant-like stone beetles (Coleoptera: Staphylinidae: Scydmaeninae)
}

\author{
PAWEE JAŁOSZYŃSKI ${ }^{1}$ and ALEKSANDRA KILIAN ${ }^{2}$
}

\begin{abstract}
${ }^{1}$ Museum of Natural History, Wrocław University, Sienkiewicza 21, 50-335 Wrocław, Poland; e-mail: scydmaenus@yahoo.com
${ }^{2}$ Department of Invertebrate Biology, Evolution and Conservation, Wrocław University, Przybyszewskiego 63/77, 51-148 Wrocław, Poland; e-mail: a.kilian@biol.uni.wroc.pl
\end{abstract}

Key words. Coleoptera, Staphylinidae, Scydmaeninae, Scydmaenini, Scydmaenus, Palaearctic, larval morphology, behaviour, feeding

\begin{abstract}
Morphology of mature larvae of two Central European species of Scydmaenus Latreille is described and illustrated: $S$. (s. str.) tarsatus Müller \& Kunze and S. (Cholerus) hellwigii (Herbst). Inaccuracies in previous descriptions of S. tarsatus are discussed and the following combination of characters is defined as diagnostic for Scydmaenus: epicranial sutures reaching posteromedian margins of antennal insertions; presence of a single pair of stemmata and epicranial supraantennal pits; anterior row of subtriangular teeth on epipharynx; mandibles falciform and without mesal teeth; antennomere 3 rudimentary; antennal sensory appendage subconical and asymmetrical; maxilla with galea and lacinia; labium strongly constricted between mentum and prementum; thoracic tergites undivided along midline; head capsule, thoracic tergites, laterotergites and abdominal segments except sternite 1 densely setose; thoracic sternites and abdominal sternite 1 largely asetose; and lack of urogomphi. We also describe the feeding behaviour of immature $S$. tarsatus and demonstrate for the first time that Scydmaeninae larvae can feed on live springtails and not armoured mites. In the introduction we provide a summary of the literature on all hitherto known preimaginal stages of Scydmaeninae.
\end{abstract}

\section{INTRODUCTION}

Scydmaeninae is a large subfamily of Staphylinidae, comprising nearly 4900 species in about 90 genera and ten tribes (Grebennikov \& Newton, 2009). Larval morphology of ant-like stone beetles, however, is very poorly known. To date, various authors have published descriptions and illustrations of larvae of only twelve genera and less than $0.5 \%$ of known species. Some published figures are highly simplified and some misleading, with morphological structures misinterpreted or taxa misidentified [e.g., a larva of the oxyteline staphylinid Syntomium Curtis assigned to Euconnus Thomson (Schmid, 1988a; Newton \& Franz, 1998)]. Furthermore, descriptions based on immature stages obtained ex ovo by rearing beetles are scarce and identifications based solely on the cooccurrence of larvae and adults may be unreliable. All larval stages and the pupa are described only for a single species (De Marzo, 1984) and only for one species are the details of the chaetotaxy illustrated and described using modern methods (Wheeler \& Pakaluk, 1983). Although larval characters of Scydmaeninae were recently used in an extensive phylogenetic analysis (Grebennikov \& Newton, 2009) and may be crucial for clarifying suprageneric relationships within this subfamily, such data is scarce, which hampers further taxonomic study.

In 1882 Tömösvary described a family Anisosphaeridae in Thysanura for a new genus, Anisosphaera, an oddlooking arthropod from North-Eastern Slovakia. Silvestri (1899) placed this family in Anisosphaeridia, a new insect order, with possible affinities to Collembola. Bergroth
(1899) recognized in Anisosphaera a larva belonging to a scydmaenine genus, Cephennium Müller \& Kunze, and synonymized these names; an additional discussion supporting this action was published by Dudich (1927). The larvae of Cephennium were the first to be described and are still the best known among the Scydmaeninae, with various morphological details illustrated for four species (Peyerimhoff, 1899; Jeannel, 1909; Scholz, 1926; Ionesco, 1937; Paulian, 1941; Brown \& Crowson, 1980; Schmid, 1988a, b). In addition to Cephennium, in the tribe Cephenniini there are only illustrations of the general habitus and a few morphological details of Cephennodes Reitter (as an unidentified genus by Morimoto \& Hayashi, 1986 and as Coatesia Scott by Newton, 1991). In Eutheiini, some details are described and illustrated for larvae of Eutheia Stephens and Veraphis Casey (Brown \& Crowson, 1980; Newton, 1991); in Cyrtoscydmini for Stenichnus Thomson, Scydmoraphes Reitter, Neuraphes Thomson and Euconnus (Paulian, 1941; Franz, 1965; Brown \& Crowson, 1980; Wheeler \& Pakaluk, 1983; Schmid, 1988a; Newton, 1991); in Scydmaenini for Scydmaenus Latreille only (Meinert, 1888; Böving \& Craighead, 1931; Jeannel \& Paulian, 1945; Brown \& Crowson, 1980; Newton, 1991; Beutel \& Molenda, 1997); and in Mastigini, Clidicini and Leptomastacini larvae of one genus in each tribe are known, respectively Palaeostigus Newton, Clidicus Laporte and Leptomastax Pirazzoli (De Marzo, 1983, 1984; Vit \& De Marzo, 1989; O'Keefe \& Monteith, 2000; Grebennikov \& Newton, 2009). Data from the above-listed literature were used by several 
authors in identification keys, reviews and summaries (e.g., Ghilarov, 1964; Kasule, 1966; Klausnitzer, 1978, 1997; Newton \& Franz, 1998, O’Keefe, 2005). Immature stages of Plaumanniolini, Chevrolatiini and Leptoscydmini remain unknown.

Data on the biology of immature Scydmaeninae, especially their behaviour and feeding preferences, are even scarcer. Schuster (1966a, b) observed larvae of Cephennium majus Reitter and $C$. thoracicum Müller \& Kunze feeding and carried out prey preference experiments. These species were found to be predacious and feed mostly on the armored mites (Oribatida), and only rarely on Uropodina and Gamasida; cannibalistic tendencies among the larvae were also mentioned (Schuster, 1966b). Schmid (1988) made similar observations on immature Cephennium, Stenichnus and Scydmoraphes. De Marzo (1983) reared larvae of Palaeostigus pilifer (Kraatz) and reported that the first and second instars feed exclusively on a secretion produced by the female abdominal gland, which was deposited along with the eggs. In the laboratory mature (i.e. third instar) larvae were fed on the viscera of a caterpillar of Galleria sp. De Marzo is so far the only author to provide photographic documentation of scydmaenine larvae feeding.

Recently Jałoszyński (2012a) reported that adults of Scydmaenus tarsatus Müller \& Kunze and Scydmaenus hellwigii (Herbst) can be maintained in long-term laboratory cultures by feeding them on soft-bodied arthropods. Neither of these species showed any interest in oribatid or uropodine mites, which have heavily sclerotized cuticles, whereas both readily fed on live hypogastrurid springatils (genus Ceratophysella Borner) and acaridid mites (genus Rhizoglyphus Claparède). Scydmaenus hellwigii also fed on dead springtails and $S$. tarsatus on dead flies, isopods and pseudoscorpions (Jałoszyński, 2012b). During these experiments, immature scydmaenine were collected together with numerous adults of $S$. tarsatus and identified as conspecific with adult beetles on the basis of previous descriptions (Meinert, 1888; Brown \& Crowson, 1980) and the fact that the substrate (decaying plant matter in a garden compost heap) was inhabited only by this species of ant-like stone beetles. During previous rearing of $S$. hellwigii adults (Jałoszyński, 2012a) a single larva was obtained. In the present paper the previously inadequately described larva of $S$. tarsatus is redescribed, and the larva of $S$. hellwigii is described for the first time. Moreover, observations on the previously unknown feeding behaviour of larval $S$. tarsatus are reported.

\section{MATERIAL AND METHODS}

\section{Material}

Larvae together with numerous adults of Scydmaenus (s. str.) tarsatus Müller et Kunze, 1822 were collected from a large compost heap at Włocławek (Central Poland) by sifting in the last week of August 2010. No other species of ant-like stone beetles were found in this substrate. Some larvae were immediately preserved in $75 \%$ ethanol for morphological study, six others were placed alive in a $150 \mathrm{ml}$ plastic container half-filled with compost and transferred to the laboratory for further observations. Numerous adults of Scydmaenus (Cholerus) hellwigii
(Herbst, 1792) were collected from rotten wood and from under loose bark of a lime tree at Wrocław-Wojnów (SW Poland) in the middle of April 2010, and transported to the laboratory in a similar manner. Scydmaenus hellwigii was reared as described previously (Jałoszyński, 2012a): 20 females and 10 males were placed in a $30 \mathrm{~cm}$ high, 11 cylindrical container $3 / 4$ filled with moist rotten lime wood inhabited by a colony of small Isotomidae springtails of the genus Desoria Agassiz \& Nicolet. The container was closed except for a $50 \times 2 \mathrm{~mm}$ ventilation opening at the top and the substrate was dampened every two weeks. Every two months the entire substrate was sifted and searched for larvae and then put back into the same container together with all the inhabitants; this culture was terminated after six months, when a larva was found. The larva was preserved in $75 \%$ ethanol. Larvae of both of the species studied were identified as last instars based on their body length, exceeding that of adults by $20-30 \%$.

\section{Preparations}

One larva of each species was macerated in warm $10 \% \mathrm{NaOH}$ after separating the head; when soft tissues had dissolved specimens were washed in distilled water, slightly stained with chlorazol black and mounted in glycerol-gelatin. Drawings and measurements were made at magnifications up to $600 \times$ using a phase contrast compound microscope.

\section{Scanning electron microscopy (SEM)}

A larva of $S$. tarsatus was transferred from ethanol to distilled water through a series of 70/40/20\% ethanol, cleaned for $1 \mathrm{~min}$ in $10 \% \mathrm{NaOH}$ at ambient temperature, washed in water, transferred to absolute ethanol through a series of $20 / 40 / 75 \%$ ethanol, kept for $1 \mathrm{~h}$ in acetone and subsequently for $1 \mathrm{~h}$ in hexamethyldisilazane. The dehydrated specimen was mounted on a SEM stub with a carbon tab and sputter-coated with gold (Pirani 501, Edwards) and then examined using a LEO 435 VP scanning electron microscope.

\section{Light photography and image processing}

Habitus images were taken using an Olympus C-750UZ digital camera with a Raynox MSN-202 close-up lens. Image stacks were processed using Combine ZP (Hadley, 2010). Final image adjustments and annotations were made in Corel PhotoPaint.

\section{Terminology and measurements}

Terminology used for the chaetotaxy follows systems proposed by Wheeler \& Pakaluk (1983), Wheeler (1990) and Kilian (2007). The total body length is the sum of the lengths of the head, thoracic and abdominal segments measured separately. The following abbreviations are used (abdominal segments, antennomeres and palpomeres are counted from base of abdomen, antenna and palp, respectively; i.e. An3L is the length of antennomere 3): AnL - length of antennomere; $\mathrm{AbL}$ - length of abdominal segment measured along midline, excluding lateral lobes projecting caudad; measurement of segment 10 does not include extruded anal membrane; AbW - width of abdominal segment; ASL - length of antennal sensory appendage; HL length of head excluding the teeth on nasale; HW - width of head; LPL - length of labial palpomere; MPL - length of maxillary palpomere; MsL - mesothoracic length; MsW - mesothoracic width; $\mathrm{MtL}$ - metathoracic length; $\mathrm{MtW}$ - metathoracic width; PL - prothoracic length; PW - prothoracic width.

\section{Observations on feeding behaviour}

Larvae of $S$. tarsatus were maintained under laboratory conditions as described previously for adults (Jałoszyński, 2012a), with minor modifications. Petri dishes (diameter $3 \mathrm{~cm}$ ) half- 


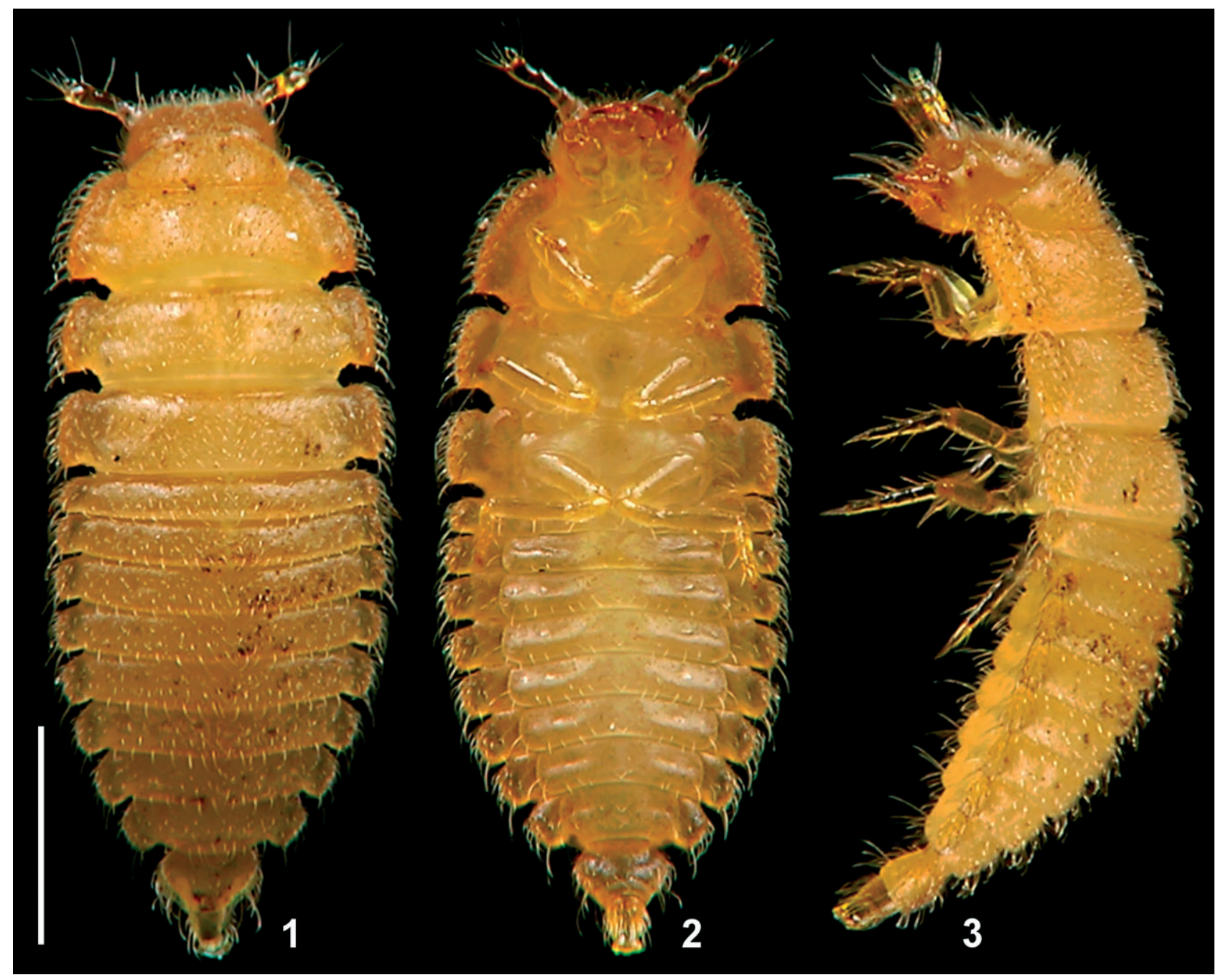

Figs 1-3. Scydmaenus tarsatus, general habitus of mature larva in dorsal (1), ventral (2) and lateral (3) views. Scale bar: $0.5 \mathrm{~mm}$.

filled with plaster of Paris were used as arenas; they were preconditioned by filling with moist compost for 2-3 days, then the compost was removed and a fresh thin, pressed layer of compost was placed on the plaster. Six larvae were observed, three in each arena; the substrate was moistened every second day with $0.2 \mathrm{ml}$ of distilled water and the Petri dishes were kept at ambient temperature $\left(22-24^{\circ} \mathrm{C}\right)$ and in the dark. Larvae were provided with a mixture of various live mites belonging to Oribatida (mostly Phthiracaridae, Galumnidae and Carabodidae), Mesostigmata (Uropodina, Parasitina) and various springtails (mostly Hypogastruridae and Tomoceridae), all collected from the compost inhabited by S. tarsatus. Prey that were not eaten were replaced every 7 days. The larvae were kept for 4 weeks and observations were made every day for long enough to witness the entire feeding process from an attack to abandoning the remnants of the prey, which takes typically $1-2 \mathrm{~h}$.

\section{RESULTS}

\section{Redescription of mature larva of Scydmaenus tarsatus}

Body (Figs 1-3). Total body length $2.690 \mathrm{~mm}$. Elongate, strongly flattened, distinctly more convex dorsally than ventrally, nearly parallel-sided up to abdominal segment 5, abdominal segments 6-10 gradually narrowing; pigmentation yellowish-brown; integument weakly sclerotized, densely setose; all setae simple (i.e., non- modified, slender and pointed at apex); most setae on head, thoracic and abdominal segments inserted on distinct protuberances (papillae). Tergal and sternal plates distinct and undivided along midline. Microsculpture absent except for fine isodiametric granulation on bases of abdominal segments 9 and 10. Head capsule (except for anterior part of frontoclypeal region), tergal and sternal plates of thorax and abdomen densely covered with fine microtrichia (Figs 5, 8).

Head (Figs 4, 5, 10-14). Prognathous, nearly as wide as long, nearly half as wide as prothorax, broadest near middle, distinctly flattened; HL $0.344 \mathrm{~mm}$, HW 0.364 $\mathrm{mm}, \mathrm{HL} / \mathrm{HW}$ 0.94. Small, single stemma located dorsolaterally to each antennal insertion; stemmata distinctly darker than surrounding cuticle. Epicranial stem long, almost half as long as cranium. Epicranial sutures nearly straight, V-shaped, anteriorly nearly reaching antennal insertions; accompanied by a small epicranial supraantennal pit. Each epicranial plate with about 30 mostly asymmetrically distributed setae, and a dorsolateral cluster of five dome-shaped structures (Fig. 5); frons with about 30 mostly asymmetrically distributed setae. Anterior part of frontoclypeal region (nasale) (Fig. 11) with 8 teeth of various sizes located below distinct transverse 


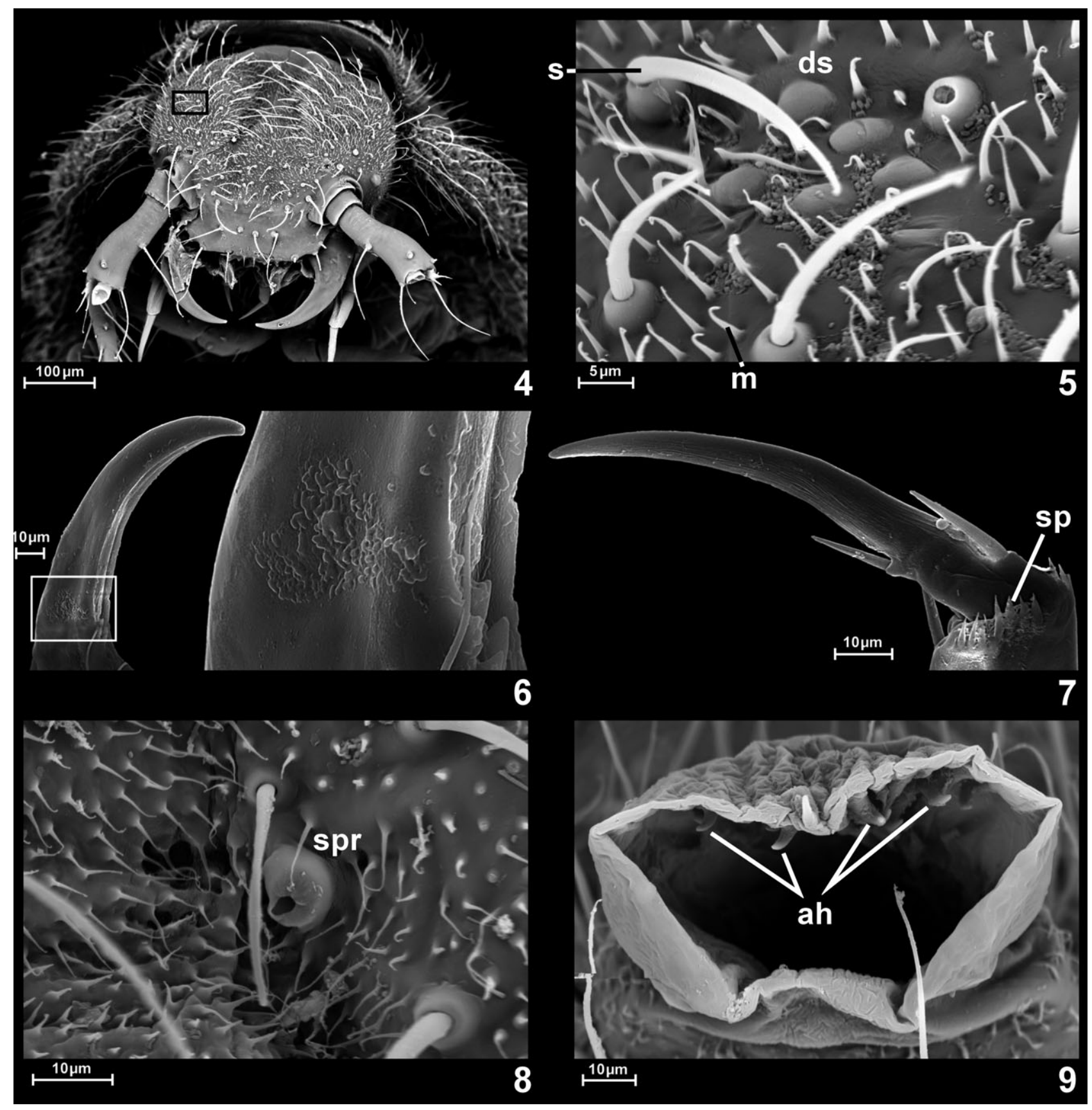

Figs 4-9. Scydmaenus tarsatus. 4 - dorsal view of head, and apical part of prothorax (framed area enlarged in Fig. 5); 5 - details of epicranial plate (magnified framed area from Fig. 4) with dome-shaped structures, microtrichia and setae; 6 - left mandible in dorsal view, framed area magnified; 7 - pretarsus and spines of tibiotarsus; 8 - spiracle on abdominal laterotergite $4 ; 9$-anal membrane with internal hooks. Abbreviations: ah - hook of anal membrane; $\mathrm{ds}$ - dome-shaped structures; $\mathrm{m}$ - microtrichium; $\mathrm{s}-\mathrm{seta} ; \mathrm{sp}$ - apical spine; spr - spiracle.

marginal ridge but well-visible in dorsal view, two pairs of fine marginal setae, three pairs of long anterior setae and two pairs of long sub-anterior setae. Ventral side (Fig. 12): posterior tentorial pits well-visible at base of mouthparts; each lateromedian part of cranium (gena) with 9-14 asymmetrically distributed setae and two pores lateral to mouthparts, posterior part of cranium asetose. Tentorium (Figs 13, 14) with broad and long anterior and posterior tentorial arms and very slender and curved dorsal tentorial arms. Tentorial bridge was not found in our preparations.
Antenna (Fig. 15). An1L $0.034 \mathrm{~mm}$, An2L $0.137 \mathrm{~mm}$, An3L $0.012 \mathrm{~mm}$ and ASL $0.032 \mathrm{~mm}$. Antennomere 1 short, with one dorsal seta. Antennomere 2 almost 4 times as long as 1, with long dorsal lateral seta, two long dorsal sub-apical setae, two long apical setae, one short ventral sub-apical seta, wide and short antero-dorsal conical sensory appendage and a very small conical sensillum at its base. Antennomere 3 very small and short with one short basal seta and three apical pointed processes.

Labrum. Fused with frontoclypeal region. Epipharynx (Fig. 16) with dense microtrichia directed antero-mesally. 


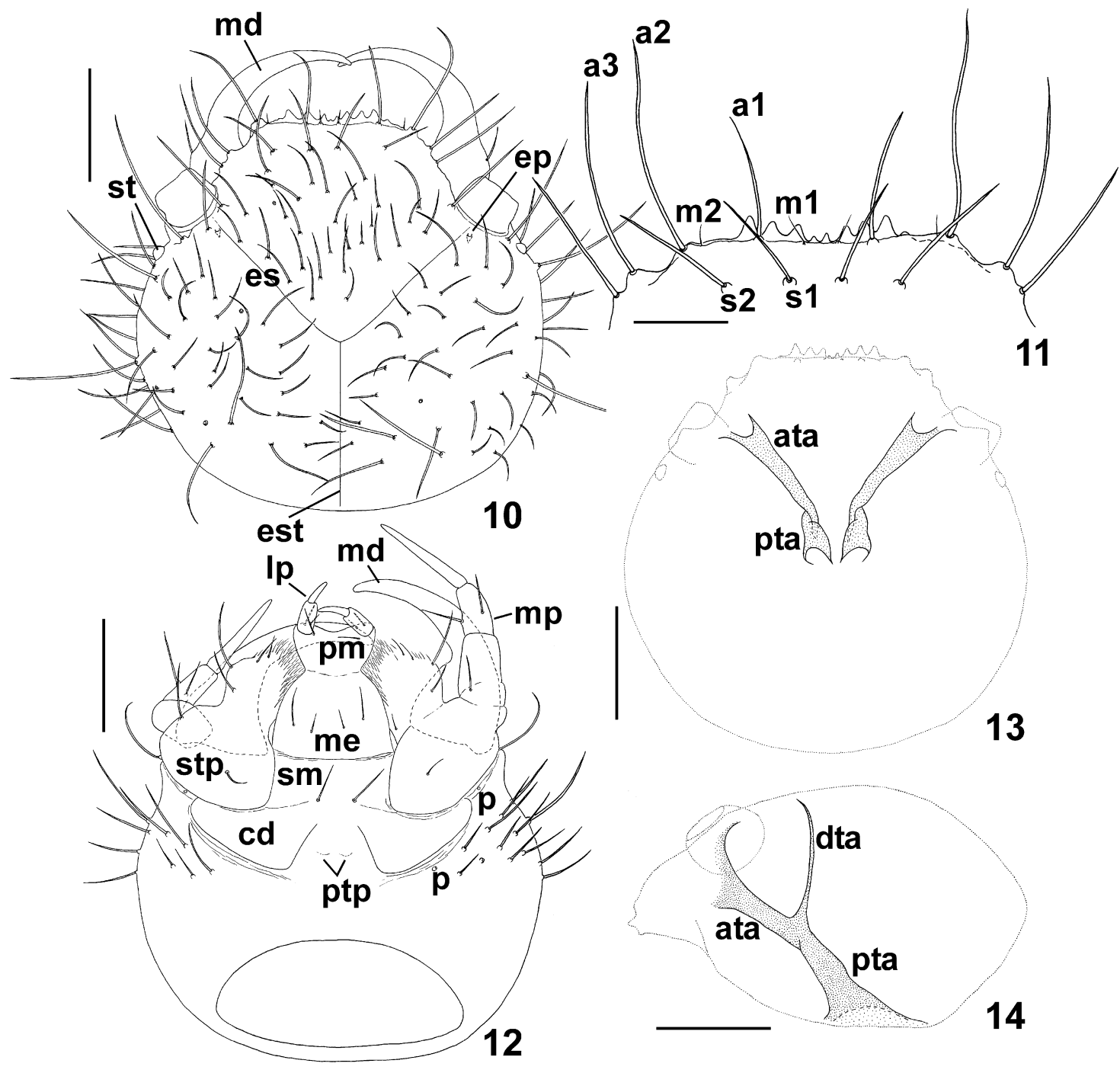

Figs 10-14. Scydmaenus tarsatus. 10 - head in dorsal view; 11 - nasale in dorsal view; 12 - head with mouthparts in ventral view; 13 - tentorium in dorsal view; 14 - tentorium in lateral view. Abbreviations: a1-3 - anterior setae; ata - anterior tentorial arm; cd cardo; dta - dorsal tentorial arm; ep - epicranial pit; es - epicranial suture, est - epicranial stem; lp - labial palp; m1-2 - marginal setae; $\mathrm{md}$ - mandible; me - mentum; $\mathrm{mp}$ - maxillary palp; $\mathrm{p}$ - pore; $\mathrm{pm}$ - prementum; pta - posterior tentorial arm; ptp - posterior tentorial pits; s1, s2 - sub-anterior setae; sm - submentum; st - stemma; stp - stipes. Scale bars: 10, 12-14: 0.1 mm; $11: 0.05 \mathrm{~mm}$.

Mandibles (Figs 4, 6, 17). Slightly darker than body, slightly asymmetrical, each falciform, with broad base and slender distal part; apices blunt, mesal margin sharp, external margin with single sub-basal seta, dorsal surface with single sub-basal dome-shaped structure and a patch of irregular microsculpture near base (Fig. 6).

Maxilla (Fig. 18). Cardines mesally fused to submentum. Stipes broad and short, with two setae, bearing large stipital projection with galea and lacinia. Lacinia with dense and long apical trichia, its basal part and distal part of galea with dense and short trichia, base of galea with two short marginal setae; outer margin of stipital projection with one long marginal seta, its ventral surface with two sub-basal setae. Maxillary palp inserted on distinct palpifer with one seta; three-segmented, MP1L 0.037 $\mathrm{mm}, \mathrm{MP} 2 \mathrm{~L} 0.050 \mathrm{~mm}$ and MP3L $0.081 \mathrm{~mm}$; palpomere 1 slightly longer than wide, asetose; 2 elongate and slightly narrowing towards apex, with two sub-median setae; 3 strongly elongate and slender, nearly straight, with single basal seta.

Labium (Figs 19, 20). Elongate, lightly sclerotized. Submentum fused to cardines, with one basal pair of setae. Mentum narrowing anteriorly, with two submedian pairs of setae. Prementum broadening anteriorly, indistinctly demarcated from mentum, with broadly emarginated anterior margin, with one lateral pair of subanterior ventral setae and two lateral pairs of anterior dorsal setae; ligula absent. Labial palps two-segmented, LP1L $0.033 \mathrm{~mm}$ and LP2L $0.028 \mathrm{~mm}$; palpomere $1 \mathrm{sub}-$ cylindrical and asetose, 2 narrower than 1 but similar in length, sub-conical. Hypopharynx (Fig. 20) with two transverse rows of fine microtrichia.

Legs (Figs 21-23). Five-segmented, slender, long, without microsculpture. Coxa elongate, with 11-13 setae of various lengths. Trochanter strongly elongate, on each leg with four moderately long setae distributed sub- 

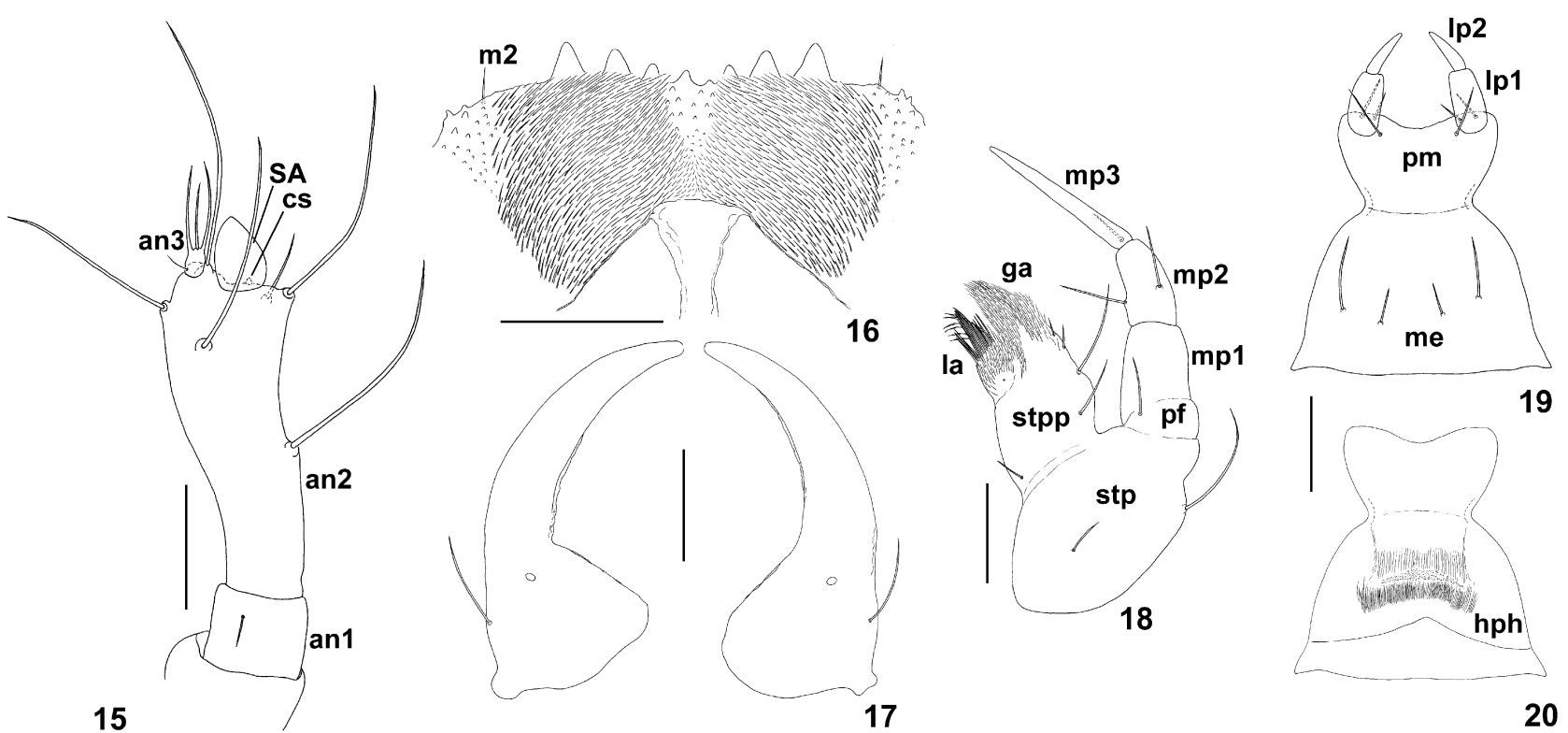

Figs 15-20. Scydmaenus tarsatus. 15 - right antenna in dorsal view; 16 - epipharynx; 17 - mandibles in dorsal view; 18 - left maxilla in ventral view; 19 - labium in ventral view; 20 - hypopharynx. Abbreviations: an1-3 - antennomeres 1-3; cs - conical sensillum; ga - galea; la - lacinia; hph - hypopharynx; lp1-2 - labial palpomere 1-2; me - mentum; mp1-3 - maxillary palpomere 1-3; pf - palpifer; pm - prementum; SA - sensory appendage; stp - stipes; stpp - stipital projection. Scale bars: $0.05 \mathrm{~mm}$.

medially and apically and one strikingly long subapical seta. Femur strongly elongate, on each leg with 5-6 setae. Tibiotarsus strongly elongate, as long as femur or slightly longer (metathoracic legs), on each leg with 11 setae and fine apical spines (Fig. 7). Pretarsus (Fig. 7) long and curved, pointed, with two setae.

Prothorax (Figs 24, 27). Transverse, expanded laterally; PL $0.344 \mathrm{~mm}$, PW $0.657 \mathrm{~mm}$ and PL/PW 0.523. Pronotum (Fig. 24) with convex tergal plate occupying posterior half of dorsum and large, convex anterior part; setae distributed asymmetrically, partly forming irregular transverse rows, setae subequal in length and diameter except 2-3 slightly thicker and longer setae located on each lateroposterior corner of pronotum; ca. 80 setae on anterior part, ca. 110 on tergal plate; laterotergite with ca. 50 setae along lateral margin, ca. 12 dorsal setae and ca. 20 ventral setae of various sizes. Basisternum (Fig. 27) with five setae forming arcuate transverse row. Pleurites (Fig. 27) with one seta on episternum and one seta on epimeron.

Mesothorax (Figs 25, 28). Transverse, expanded laterally; MsL $0.294 \mathrm{~mm}$, MsW $0.734 \mathrm{~mm}$ and MsL/MsW 0.400. Mesonotum (Fig. 25) with tergal plate occupying $3 / 4$ of its posterior part; setae distributed asymmetrically, partly forming irregular transverse rows, setae subequal in length and diameter except two slightly thicker and longer setae located on each lateroposterior corner and two pairs of short and thin anterolateral pretergal setae; tergal plate with ca. 90 setae; each laterotergite with ca. 12 dorsal setae, ca. 15 ventral and ca. 30-40 lateral setae. Median part of sternum (Fig. 28) with three pairs of setae. Episternum with two setae; epimeron asetose.

Metathorax (Figs 26, 29). Transverse, expanded laterally; MtL $0.269 \mathrm{~mm}$, MtW 0.794 and MtL/MtW 0.339 . Metanotum (Fig. 26) with tergal plate occupying 2/3 of its posterior part, narrower than mesonotal tergal plate. Setae similar to those on mesonotum (ca. 80 setae on tergal plate); median part of sternite (Fig. 29) with irregular transverse row of 7 setae; episternum with two setae; epimeron with one seta.

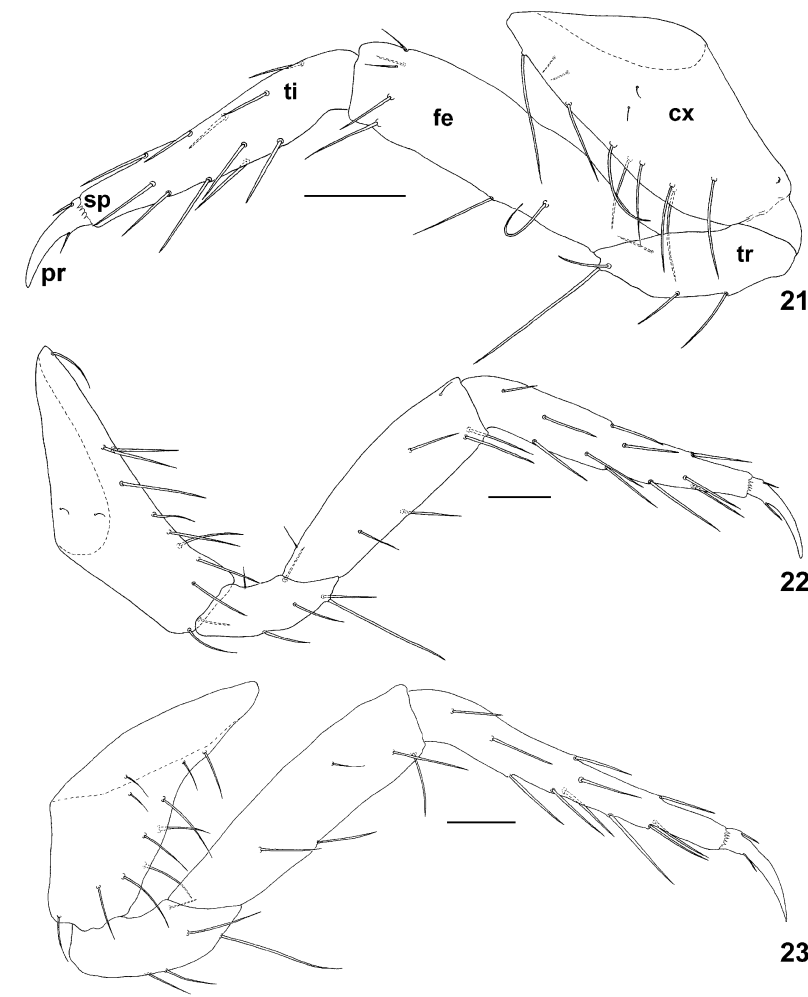

Figs 21-23. Scydmaenus tarsatus. 21 - left prothoracic leg in posterior view; 22 - right mesothoracic leg in posterior view; 23 - right metathoracic leg in posterior view. Abbreviations: cx coxa; fe - femur; $p r$ - pretarsus; $\mathrm{sp}$ - spine; ti - tibiotarsus; tr trochanter. Scale bars: $0.05 \mathrm{~mm}$. 

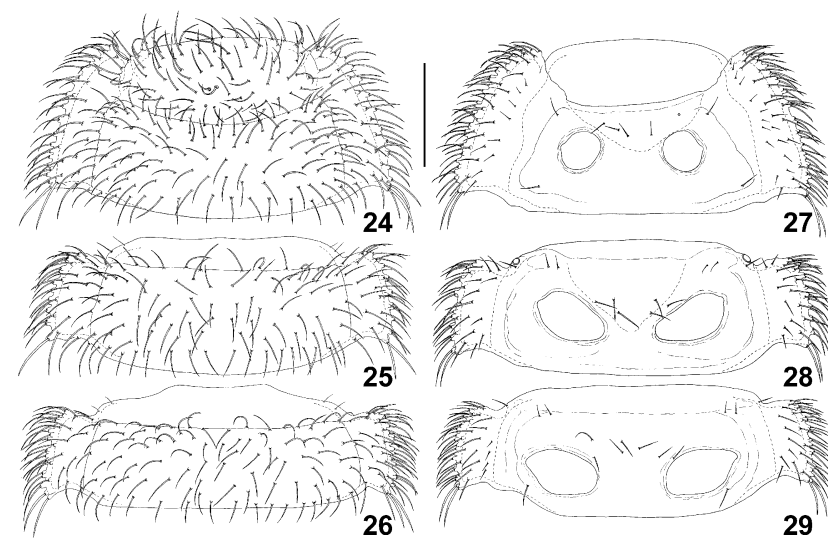

Figs 24-29. Scydmaenus tarsatus, thoracic segments in dorsal (24-26) and ventral (27-29) views. 24, 27 - prothorax; 25, 28 mesothorax; 26, 29 - metathorax. Scale bar: $0.2 \mathrm{~mm}$.

Abdominal tergites 1-8 (Figs 30-34, 40-42). Tergites strongly transverse, expanded laterally, tergal plates distinct only on tergites $1-4$ (Figs 30-33); tergites 6-8 (Figs 40-42) gradually narrowing and becoming longer. Ab1L 0.139, Ab1W $0.750 \mathrm{~mm}$; Ab1L/Ab1W 0.185; Ab2L $0.151 \mathrm{~mm}, \mathrm{Ab} 2 \mathrm{~W} 0.800 \mathrm{~mm}, \mathrm{Ab} 2 \mathrm{~L} / \mathrm{Ab} 2 \mathrm{~W} 0.189$; Ab3L $0.150 \mathrm{~mm}, \mathrm{Ab} 3 \mathrm{~W} 0.812 \mathrm{~mm}, \mathrm{Ab} 3 \mathrm{~L} / \mathrm{Ab} 3 \mathrm{~W} 0.185$; Ab4L 0.133, Ab4W 0.781, Ab4L/Ab4W 0.170; Ab5L 0.147 mm, Ab5W 0.762, Ab5L/Ab5W 0.193; Ab6L 0.128 mm, Ab6W 0.687, Ab6L/Ab6W 0.186; Ab7L $0.145 \mathrm{~mm}$, Ab7W 0.594, Ab7L/Ab7W 0.244; Ab8L $0.145 \mathrm{~mm}$, Ab8W $0.456 \mathrm{~mm}$ and Ab8L/Ab8W 0.318. Setae numerous and forming three irregular, transverse rows, subequal in length and diameter, with two exceptions: two slightly thicker and longer setae located on each lateroposterior corner of laterotergite, and 1-2 pairs of short and thin anterolateral pretergal setae. Tergites 1-4 each with ca. 50 setae on tergal plate; each laterotergite with ca. five dorsal, ca. 15 lateral and 4-10 ventral setae; pretergal setae: two pairs on tergite 1 , one pair on tergites 2 , 4-6, absent on tergites 3, 7-8. Tergites 5-8 with decreasing number of setae (40-28), each laterotergite with five dorsal, ca. 10 lateral and five ventral setae.
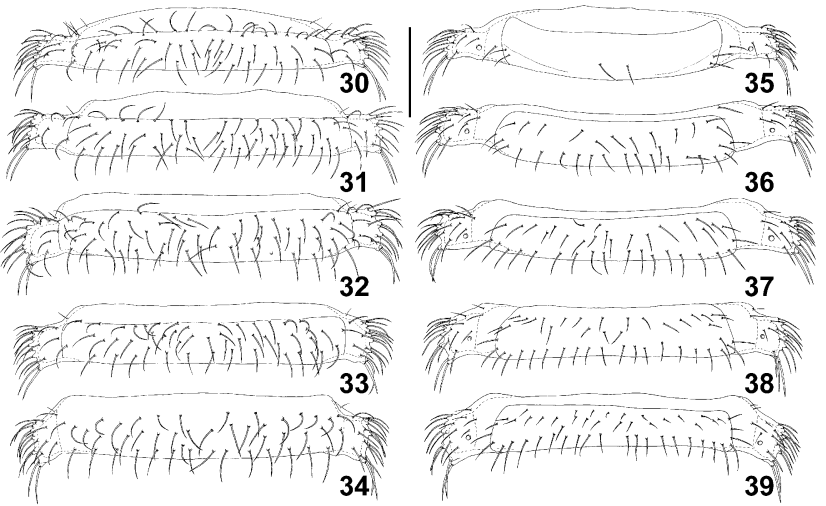

Figs 30-39. Scydmaenus tarsatus, abdominal segments $1-5$ in dorsal (30-34) and ventral (35-39) views. 30, 35 - segment 1 ; 31,36 - segment $2 ; 32,37$ - segment $3 ; 33,38$ - segment $4 ; 34$, 39 - segment 5. Scale bar: $0.2 \mathrm{~mm}$.

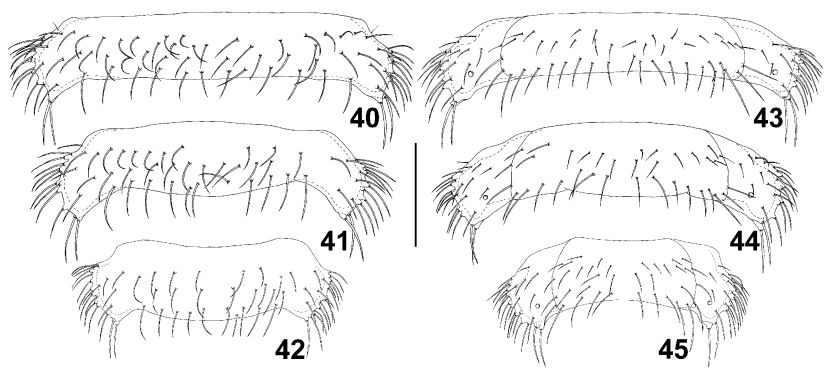

Figs 40-45. Scydmaenus tarsatus, abdominal segments $6-8$ in dorsal (40-42) and ventral (43-45) views. 40, 43 - segment 6; 41,44 - segment 7; 42, 45 - segment 8 . Scale bar: $0.2 \mathrm{~mm}$.

Abdominal sternites 1-8 (Figs 35-39, 43-45). Strongly transverse, sternal plates distinct. Sternite 1 (Fig. $35)$ with scarce setae: one pair of setae in middle and two pairs postero-laterally. Sternites 2-8 (Figs 36-39, 43-45) with numerous setae in irregular, transverse rows: anterior row with 6-12 setae, posterior row with 8-10 setae, except sternite 8 with 36 setae forming distinct lateral groups.

Abdominal segment 9 (Figs 46, 47). Subtrapezoidal, slightly wider than long, narrowing caudad and with rounded posterior margin; Ab9L $0.200 \mathrm{~mm}$, Ab9W 0.272 $\mathrm{mm}$ and $\mathrm{Ab} 9 \mathrm{~L} / \mathrm{Ab} 9 \mathrm{~W} 0.735$; tergal plate (Fig. 46) indistinct; setae numerous (ca. 50) and distributed along lateral and posterior margin; median part largely asetose. Sternite (Fig. 47) similar in shape, with ca. 60 setae irregularly distributed on median and lateral parts, apical part only with marginal setae.

Abdominal segment 10 (Figs 9, 48, 49). Subconical, distinctly longer than wide and slightly narrowing posteriorly; Ab10L $0.098 \mathrm{~mm}$, Ab10W $0.90 \mathrm{~mm}$ and Ab10L/Ab10W 1.089; tergite (Fig. 48) with 8-9 long

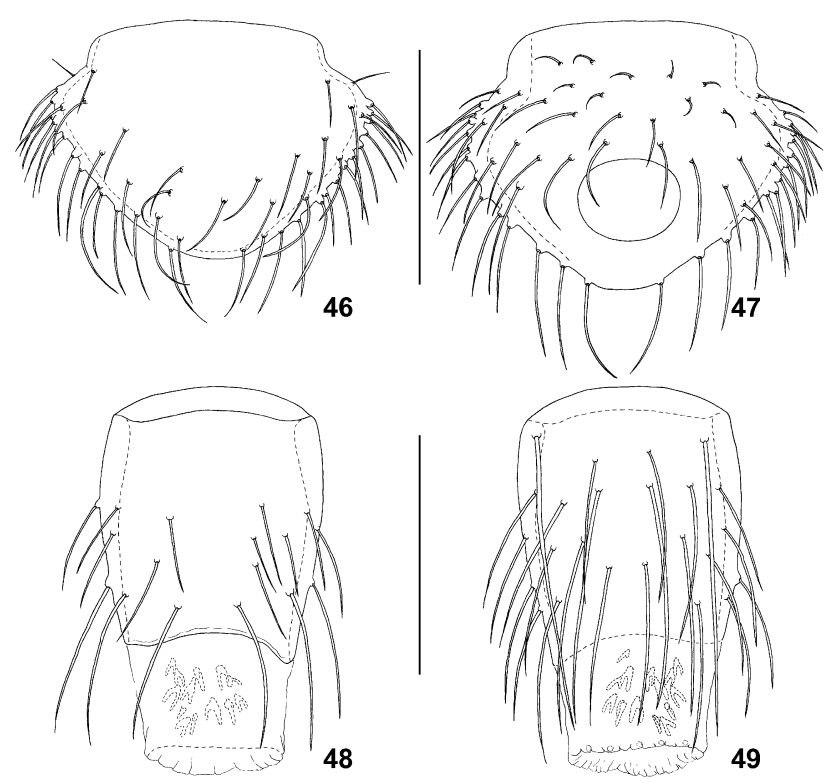

Figs 46-49. Scydmaenus tarsatus, abdominal segments 9-10 in dorsal $(46,48)$ and ventral $(47,49)$ views. 46-47 - segment 9; 48-49 - segment 10. Scale bar: 46-47: $0.2 \mathrm{~mm}$; 48-49: 0.1 $\mathrm{mm}$. 

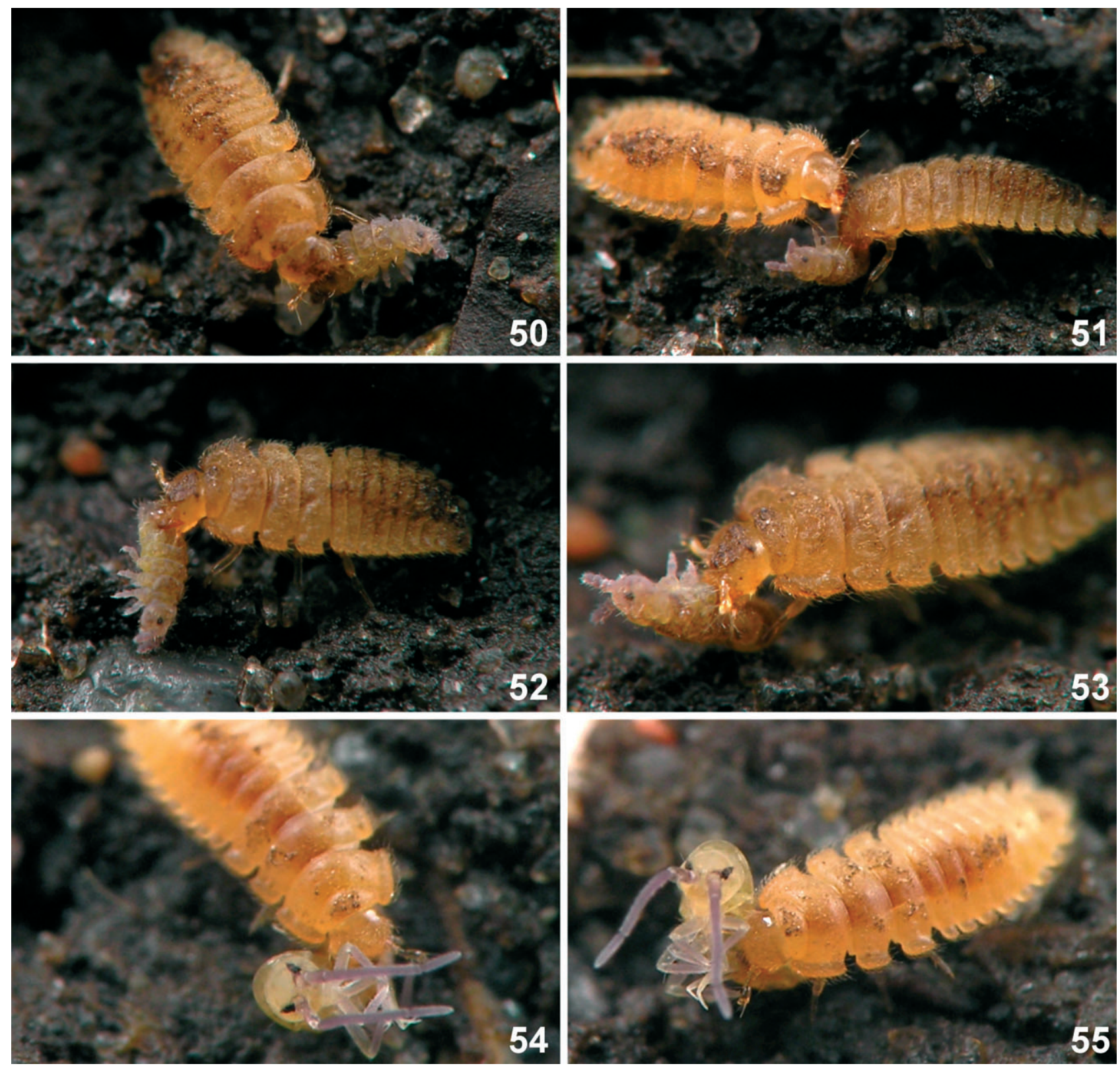

Figs 50-55. Scydmaenus tarsatus feeding on Ceratophysella (50-53) and Tomocerus (54-55) springtails.

setae on each side, with largely asetose posterior and median part; sternite (Fig. 49) with 12 long setae on each side, with particularly long posterior and median setae. Anal membrane with ca. 14 ventral, darkly sclerotized hooks inside (Fig. 9) and five ventral marginal pores.

Spiracles (Figs 8, 28, 35-39, 43-45). Annular, nine pairs of ventrolateral spiracles: one on mesothorax, on anterior protuberance of laterotergite, with one seta at posterior margin of spiracular stalk, eight pairs of spiracles on abdominal segments 1-8 located sub-medially or posteriorly on laterotergites.

\section{Feeding behaviour of immature Scydmaenus tarsatus}

The only prey observed to be attacked and eaten by larvae of $S$. tarsatus were live springtails: Ceratophysella denticulata (Bagnall, 1941) (Hypogastruridae) (Figs 50-53) and Tomocerus sp. (Tomoceridae) (Figs 54-55).
Although after 7 days some mites were found dead, their bodies were apparently intact and undamaged. Larvae did not show any interest in mites present in the arena, but readily attacked springtails. All Collembola attacked and devoured were smaller than the Scydmaenus larvae, typically about $1-1.5 \mathrm{~mm}$ in length. Beetle larvae actively searched for prey by patrolling the arena and the springtails they encountered were usually attacked from behind or from the side. During four weeks, the entire feeding from attack to abandoning the remains of the prey was observed 22 times. In each case the first contact with maxillary palps was immediately followed by a quick grip with mandibles; the feeding time depended on the size of prey captured and was from about 20 to $50 \mathrm{~min}$. During this time the prey showed irregular movements for several minutes. The Scydmaenus larvae frequently changed their grip on their prey during feeding (often turning the 


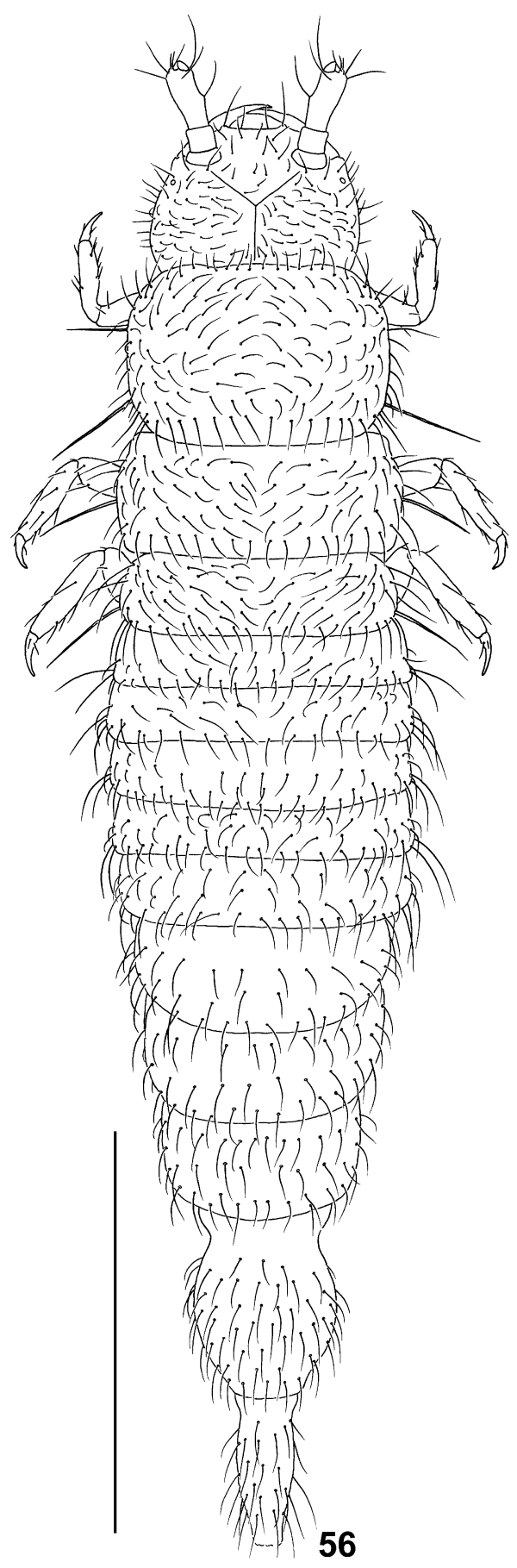

Fig. 56. Scydmaenus hellwigii, habitus of larva in dorsal view. Scale bar: $0.5 \mathrm{~mm}$.

springtail upside down and consuming it from the ventral surface) and chewing intensively with their mandibles. The prey was devoured nearly completely; the abandoned remains were not recognizable as a springtail.

\section{Description of mature larva of Scydmaenus hellwigii}

Body (Fig. 56). Total body length $2.31 \mathrm{~mm}$. Strongly elongate, sub-cylindrical and only slightly flattened, more convex dorsally than ventrally, nearly parallel-sided up to abdominal segment 2 , remaining part of abdomen gradually narrowing; pigmentation creamy-white; integument
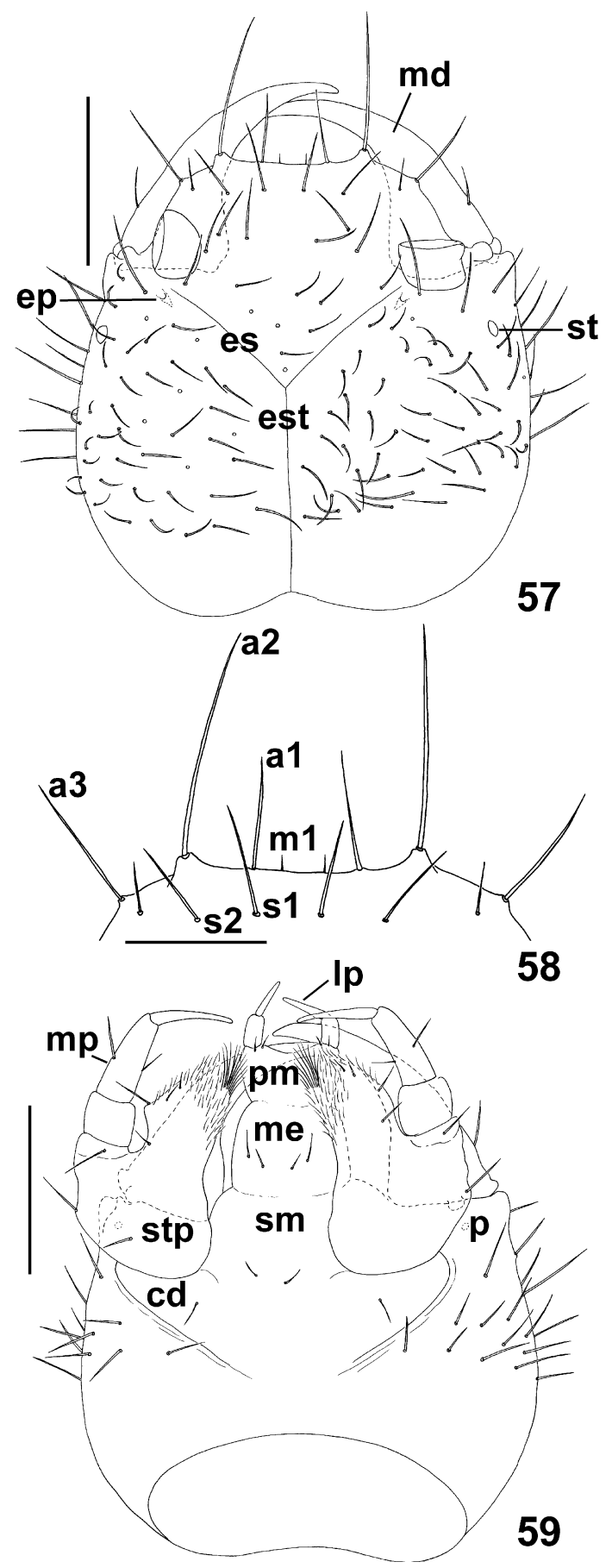

Figs 57-59. Scydmaenus hellwigii. 57 - head in dorsal view; 58 - nasale in dorsal view; 59 -head with mouthparts in ventral view. Abbreviations as in Figs 10-14. Scale bars: 57, 59: $0.1 \mathrm{~mm}$; 58: $0.05 \mathrm{~mm}$.

weakly sclerotized, densely setose, all setae simple (i.e., non-modified, slender and pointed at apex) and with simple (i.e., not papillate) insertions. Tergal and sternal plates indistinct and undivided along midline. Microsculpture absent except for fine isodiametric granulation on bases of abdominal segments 9 and 10 and most of the surface of abdominal sternite 9 . There are no microtrichia on the body segments. 

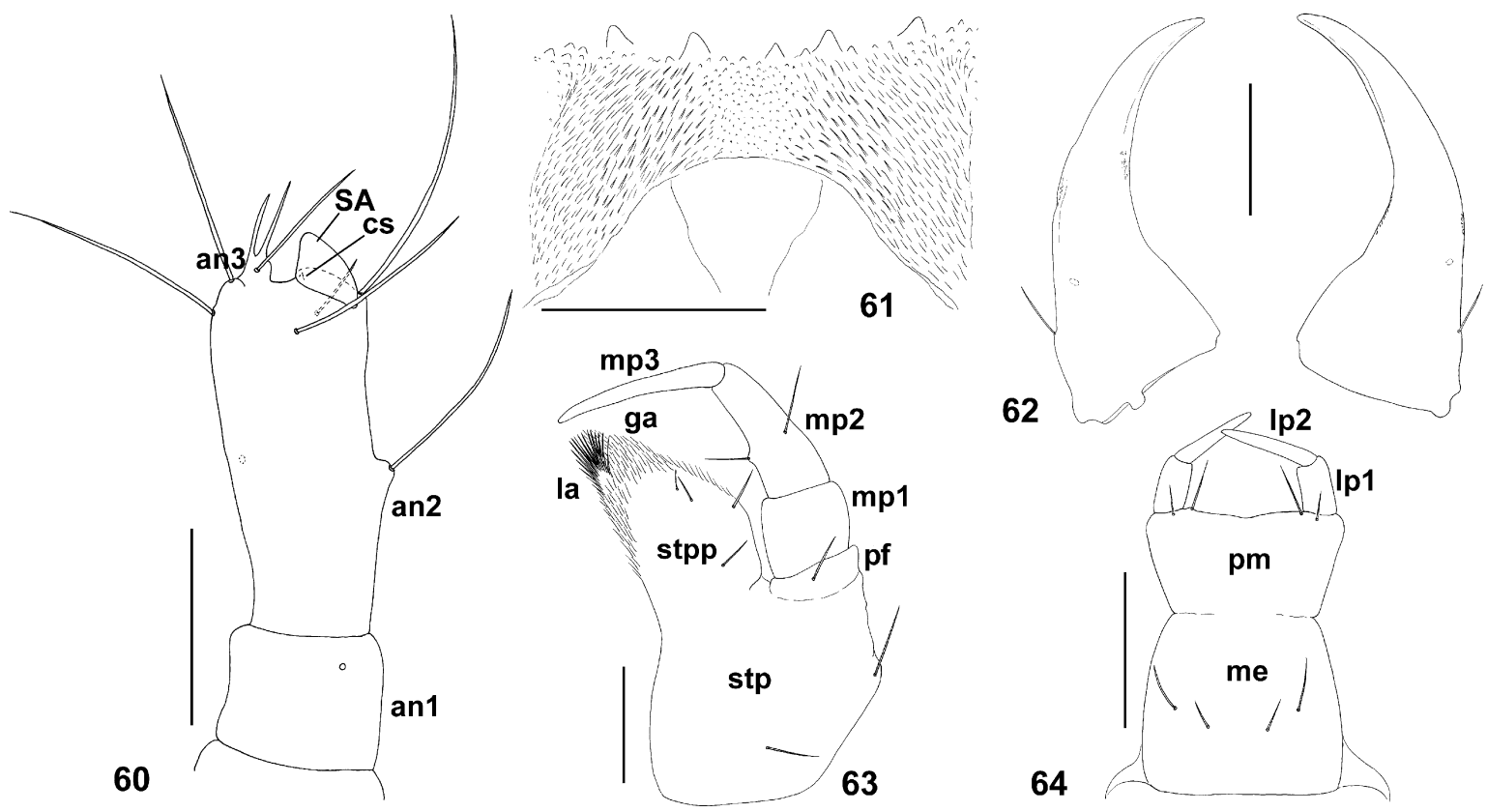

Figs 60-64. Scydmaenus hellwigii. 60 - right antenna in dorsal view; 61 - epipharynx; 62 - mandibles in dorsal view; 63 - right maxilla in ventral view; 64 - labium in ventral view. Abbreviations as in Figs 15-20. Scale bars: $0.05 \mathrm{~mm}$.

Head (Figs 57-59). Prognathous, nearly as wide as long, only slightly narrower than prothorax, broadest slightly posterior to middle, distinctly flattened; HL 0.264 $\mathrm{mm}$, HW $0.269 \mathrm{~mm}$ and HL/HW 0.981. Small, single stemma located dorso-laterally and posteriorly to each antennal insertion; stemmata distinctly darker than surrounding cuticle. Epicranial stem long, about half as long as cranium. Epicranial sutures nearly straight, v-shaped, anteriorly nearly reaching antennal insertion, accompanied by a small epicranial supra-antennal pit. Each epicranial plate with $40-50$ mostly asymmetrically distributed setae; frons with ca. 25 setae. Anterior part of frontoclypeal region (nasale) (Fig. 58) with five large teeth located below distinct transverse marginal ridge and not visible in dorsal view, one pair of fine marginal setae, three pairs of long anterior setae and two pairs of long sub-anterior setae. Ventral side (Fig. 59): tentorial pits not visible; each latero-median part of cranium (gena) with ca. 10 asymmetrically distributed setae and one pore lateral to mouthparts; posterior part of cranium asetose. Tentorium similar to that in S. tarsatus (not shown).

Antenna (Fig. 60). Three-segmented, An1L $0.032 \mathrm{~mm}$, An2L $0.087 \mathrm{~mm}$, An3L $0.006 \mathrm{~mm}$ and ASL $0.018 \mathrm{~mm}$. Antennomere 1 short, with one seta. Antennomere 2 almost 3 times as long as 1, with sub-median dorsal pore, long dorsal medio-lateral seta, two long dorsal subapical setae, two long apical setae, one short ventral sub-apical seta, wide and short antero-dorsal conical sensory appendage and a very small conical sensillum at its base. Antennomere 3 very short with long sub-basal seta and two apical pointed processes.

Labrum. Fused with frontoclypeal region. Epipharynx (Fig. 61) with dense antero-mesally directed microtrichia.

Mandibles (Fig. 62). Slightly darker than body, symmetrical, each falciform, with broad base and slender

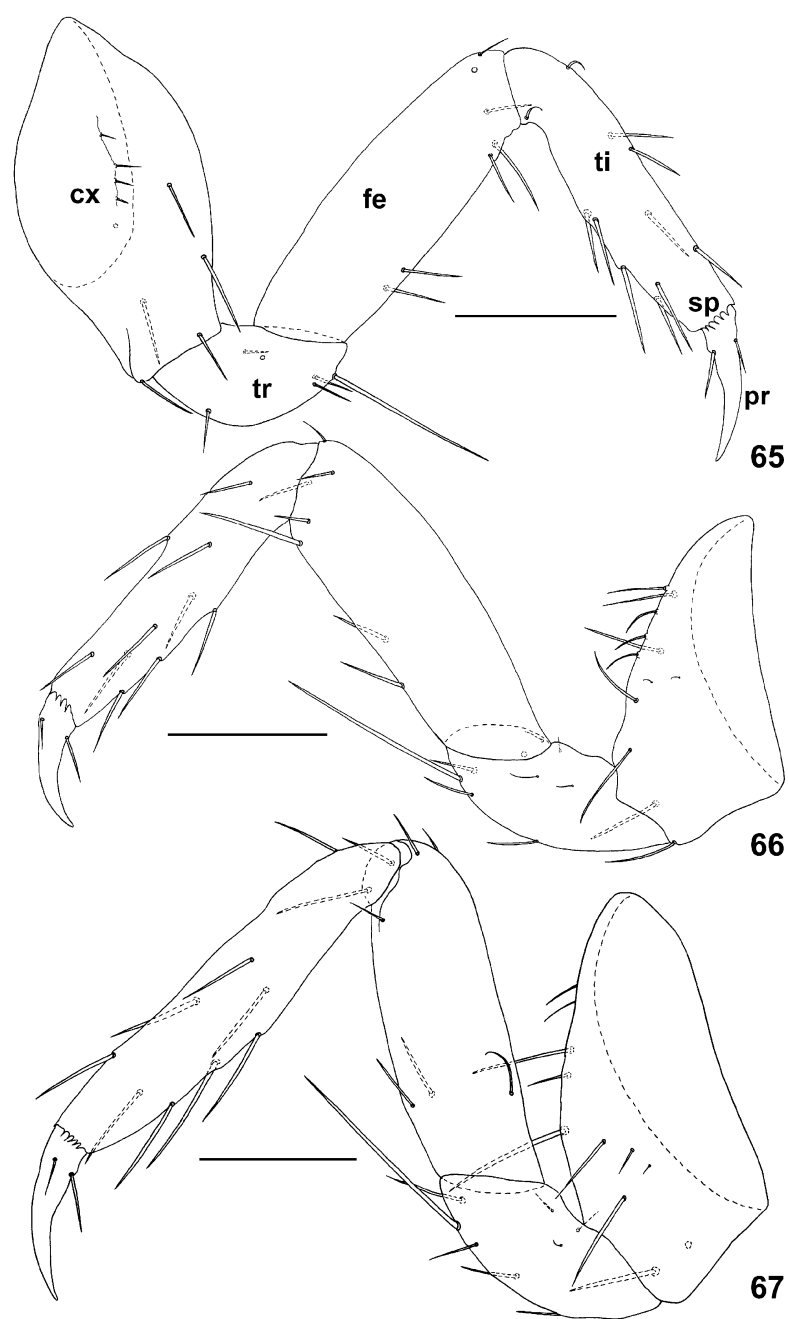

Figs 65-67. Scydmaenus hellwigii. 65 - right prothoracic leg in posterior view; 66 - left mesothoracic leg in posterior view; 67 - left metathoracic leg in posterior view. Abbreviations as in Figs 21-23. Scale bars: $0.05 \mathrm{~mm}$. 


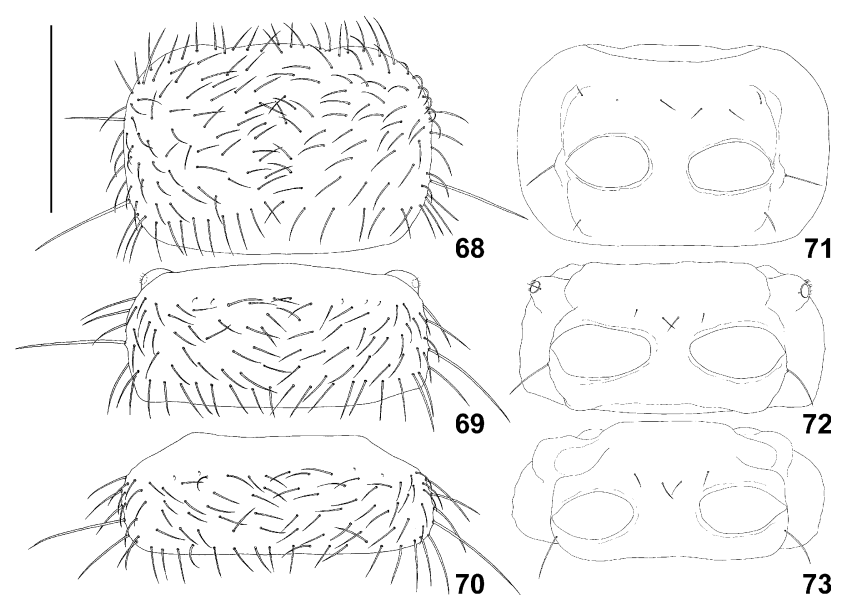

Figs 68-73. Scydmaenus hellwigii, thoracic segments in dorsal (68-70) and ventral (71-73) views. 68, 71 - prothorax; 69, 72 - mesothorax; 70, 73 - metathorax. Scale bar: $0.2 \mathrm{~mm}$.

distal part; apices pointed, mesal margin sharp, external margin with single sub-basal seta, dorsal surface with single sub-basal dome-shaped structure.

Maxilla (Fig. 63). Cardines mesally fused to submentum, each with one seta. Stipes with two setae and large projection bearing lacinia and galea. Lacinia with dense, long apical trichia, its basal part and nearly entire surface of galea with sparser and shorter trichia; base of galea with two short ventral setae; outer margin of stipital projection with one marginal seta, ventral surface of stipital projection with one sub-basal seta. Maxillary palp threesegmented, inserted on distinct palpifer with one seta; MP1L $0.031 \mathrm{~mm}$, MP2L $0.051 \mathrm{~mm}$ and MP3L $0.055 \mathrm{~mm}$; palpomere 1 short and nearly as long as broad, asetose; 2 strongly elongate and narrowing towards apex, with two sub-median setae; 3 strongly elongate, slender, slightly curved, asetose.

Labium (Fig. 64). Elongate, lightly sclerotized. Submentum fused with cardines, with one basal pair of setae. Mentum slightly narrowing anteriorly, with two submedian pairs of setae. Prementum broadening anteriorly, indistinctly demarcated from mentum, with shallowly emarginated anterior margin, with two lateral pairs of anterior setae; ligula absent. Labial palps two-segmented, LP1L $0.020 \mathrm{~mm}$ and LP2L $0.033 \mathrm{~mm}$; palpomere $1 \mathrm{sub}$ cylindrical and asetose, 2 narrower and much longer than 1, subconical. Hypopharynx (not shown) as in S. tarsatus.

Legs (Figs 65-67). Five-segmented, slender, long, without microscupture. Coxa elongate, with 9-12 setae of various sizes. Trochanter strongly elongate, on each leg with 6-8 setae of various lengths distributed sub-medially and apically and one strikingly long subapical seta. Femur strongly elongate, on each leg with seven setae. Tibiotarsus strongly elongate, as long as femur or longer (metathoracic legs), with 9-11 setae and fine apical spines. Pretarsus long and curved, pointed, with two setae.

Prothorax (Figs 68, 71). Transverse, not expanded laterally; PL $0.221 \mathrm{~mm}$, PW $0.326 \mathrm{~mm}$ and PL/PW 0.678 . Setae on pronotum (Fig. 68) numerous (77-86), distrib-

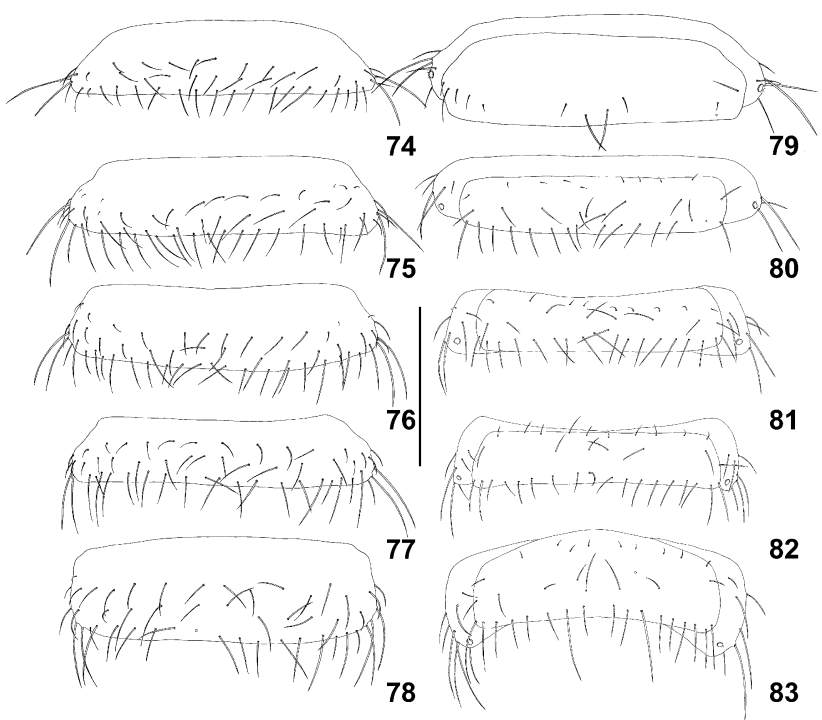

Figs 74-83. Scydmaenus hellwigii, abdominal segments $1-5$ in dorsal (74-78) and ventral (79-83) views. 74, 79 - segment $1 ; 75,80$ - segment $2 ; 76,81$ - segment $3 ; 77,82$ - segment 4 ; 78,83 - segment 5 . Scale bar: $0.2 \mathrm{~mm}$.

uted mostly asymmetrically, subequal in size except two pairs of long lateral setae. Basisternum (Fig. 71) with one pair of setae. Pleurites (Fig. 71) with two setae on each episternum, one seta on epimeron and one sub-median seta on laterotergite.

Mesothorax (Figs 69, 72). Transverse, not expanded laterally; MsL $0.169 \mathrm{~mm}, \mathrm{MsW} 0.358 \mathrm{~mm}$ and MsL/MsW 0.472; setae on mesonotum (Fig. 69) numerous (ca. 44) and arranged in several irregular transverse rows, most setae subequal in size except for 2-3 pairs of minute antero-lateral setae and enlarged lateral (marginal) setae, of which one pair is particularly long and thick. Anterior sternal part (Fig. 72) with two pairs of median setae. Each epimeron (Fig. 72) with one seta.

Metathorax (Figs 70, 73). Transverse, not expanded laterally; MtL $0.132 \mathrm{~mm}$, MtW $0.347 \mathrm{~mm}$ and MtL/MtW 0.380. Setae on metanotum (Fig. 70) and sternum (Fig. $73)$ similar to those on mesothorax.

Abdominal tergites 1-8 (Figs 74-78, 84-86). Tergites transverse (1-5 strongly, 6-7 distinctly, 8 slightly), not expanded laterally, tergal plates indistinct; tergites 1-5 (Figs 74-78) subequal in width, tergites 6-8 (Figs 84-86) gradually narrowing and becoming longer. Ab1L 0.079 mm, Ab1W 0.379 mm, Ab1L/Ab1W 0.208; Ab2L 0.096 $\mathrm{mm}, \mathrm{Ab} 2 \mathrm{~W} 0.389 \mathrm{~mm}, \mathrm{Ab} 2 \mathrm{~L} / \mathrm{Ab} 2 \mathrm{~W}$ 0.247; Ab3L 0.097 $\mathrm{mm}, \mathrm{Ab} 3 \mathrm{~W} 0.379 \mathrm{~mm}, \mathrm{Ab} 3 \mathrm{~L} / \mathrm{Ab} 3 \mathrm{~W}$ 0.256; Ab4L 0.081 mm, Ab4W 0.379 mm, Ab4L/Ab4W 0.214; Ab5L 0.129 mm, Ab5W 0.379 mm, Ab5L/Ab5W 0.340; Ab6L 0.213 mm, Ab6W 0.337, Ab6L/Ab6W 0.633; Ab7L 0.218 mm, Ab7W 0.305 mm, Ab7L/Ab7W 0.715; Ab8L 0.205, Ab8W 0.242 and Ab8L/Ab8W 0.849. Setae numerous, on each tergite arranged in three irregular, transverse, posterior rows; lateral (marginal) setae distinctly longer and thicker than dorsal ones. Tergites 1-5 with ca. 50 setae, 


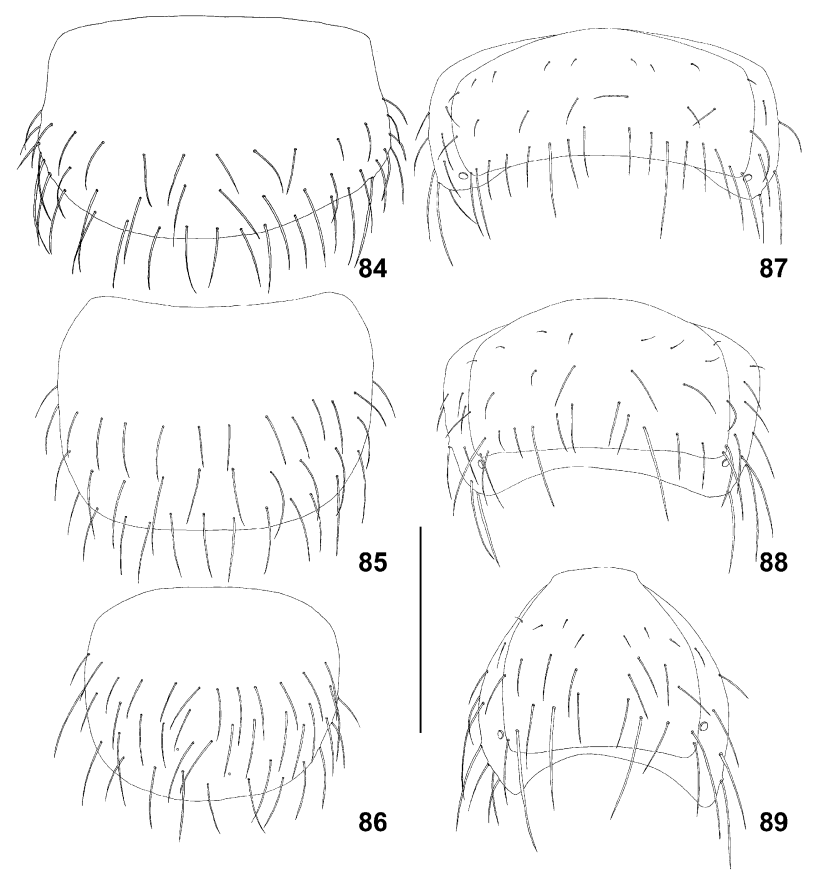

Figs 84-89. Scydmaenus hellwigii, abdominal segments 6-8 in dorsal (84-86) and ventral (87-89) views. 84, 87 - segment 6; 85, 88 - segment 7; 86, 89 - segment 8 . Scale bar: $0.2 \mathrm{~mm}$.

tergites 6-8 with ca. 40 setae; laterotergites with 3-4 lateral (marginal) setae and 2-5 ventral setae.

Abdominal sternites 1-8 (Figs 79-83, 87-89). Transverse, sternal plates distinct. Sternite 1 (Fig. 79) with few setae: two pairs of setae in middle and $2-5$ setae posterolaterally on each side. Sternites 2-8 (Figs 80-83, 87-89) with three irregular transverse rows of setae: anterior row with 7-10 short setae, median row of 4-8 long setae and posterior row of 9-18 setae of various lengths. Posterolateral and postero-submedian pairs of setae on sternites 5-8 distinctly longer than remaining setae.

Abdominal segment 9 (Figs 90, 91). Suboval with distinct sub-basal constriction, distinctly elongate; Ab9L $0.206 \mathrm{~mm}$, Ab9W 0.131 mm and Ab9L/Ab9W 1.572; tergal plate (Fig. 90) indistinct; setae numerous (52) and subequal in size, distributed in seven irregular rows on posterior 2/3 of tergite. Sternite (Fig. 91) with 36 setae of various lengths distributed asymmetrically in median parts of sternite.

Abdominal segment 10 (Figs 92, 93). Sub-conical, strongly elongate, slightly constricted in sub-basal region and strongly narrowing posteriorly; Ab10L $0.200 \mathrm{~mm}$, Ab10W $0.075 \mathrm{~mm}$ and Ab10L/Ab10W 2.667. Setae on tergite (Fig. 92) numerous (26) and subequal in length, occupying posterior 3/4 of tergite; sternite (Fig. 93) with 25 setae asymmetrically distributed laterally and in three irregular transverse rows, basal and apical parts of sternite asetose. There are no hooks on the anal membrane.

Spiracles (Figs 71, 75, 77, 79, 81, 83, 85, 87, 89). Annular, nine pairs of ventro-lateral spiracles: one on mesothorax, on prominent anterior protuberance of laterotergite, with group of fine trichia and one mesal seta; and eight pairs of spiracles postero-laterally on abdominal segments $1-8$.
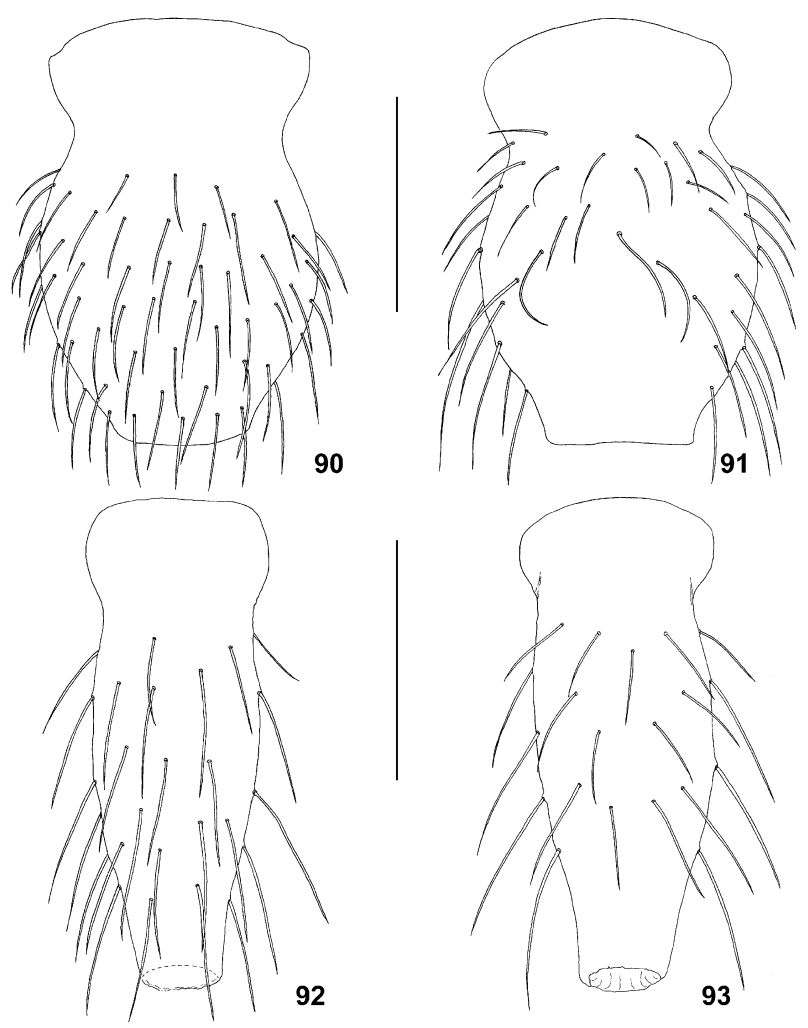

Figs 90-93. Scydmaenus hellwigii, abdominal segments 9-10 in dorsal $(90,92)$ and ventral $(91,93)$ views. 90-91 - segment 9; 92-93 - segment 10. Scale bar: $0.1 \mathrm{~mm}$.

\section{DISCUSSION}

The larva of Scydmaenus tarsatus was described by Meinert (1888) and his illustrations were redrawn several times (e.g., Ganglbauer, 1899; Larsson, 1941; Kühnelt, 1961; Ghilarov, 1964; Klausnitzer, 1978), in some cases losing or even gaining some details. Meinert's description (in Danish) is rather brief, but the genus can be determined using the figures, which are fairly accurate except that showing the stipital projection with a single apical lobe, instead of the two distinct lobes reported in the present study. Some additional details provided later by Brown \& Crowson (1980) disagree with the previous description. These authors state that the ocelli are absent, the stipital projection is illustrated with a simple subtriangular apex and the pygopod (i.e., the abdominal segment 10) with a distinct pair of lateral projections, apparently inserted on the extruded anal membrane. The present study confirms Meinert's observations concerning the presence of a pair of small stemmata (Fig. 10) and the absence of any lateral lobes or projections on the abdominal apex (Figs 48, 49). Moreover, the nasale illustrated by Brown \& Crowson is devoid of teeth, while in a slide preparation and in SEM images a row of small subtriangular teeth can be seen (Figs 4, 10, 11).

The larva of Scydmaenus tarsatus is unique among known Scydmaeninae in having distinctly separated and strongly expanded lateral parts on thoracic and abdominal segments, the protergite with a large anterior part separated from the tergal plate, the nasale with a row of teeth 
TABLE 1. Major morphological differences between larvae of S. tarsatus and S. hellwigii.

\begin{tabular}{|c|c|c|c|}
\hline & Character & S. tarsatus & S. hellwigii \\
\hline 1. & body form & $\begin{array}{l}\text { nearly onisciform, flattened and expanded } \\
\text { laterally }\end{array}$ & sub-cylindrical, not expanded laterally \\
\hline 2. & microtrichia on body segments & present & absent \\
\hline 3. & nasale & 8 teeth visible in dorsal view & 5 teeth visible only in ventral view \\
\hline 4. & setae on nasale & 2 pairs of marginal setae & 1 pair of marginal setae \\
\hline 5. & posterior tentorial pits & present & indiscernible \\
\hline 6. & $\begin{array}{l}\text { dome-shaped structures on epicranial } \\
\text { plates }\end{array}$ & present & absent \\
\hline 7. & antennomere 2 & slender, $4 \times$ An1L & stouter, $2.5 \times \mathrm{An} 1 \mathrm{~L}$ \\
\hline 8. & antennomere 3 & $\begin{array}{l}\text { with } 3 \text { apical processes and short sub-basal } \\
\text { seta }\end{array}$ & $\begin{array}{l}\text { with } 2 \text { apical processes and long sub-basal } \\
\text { seta }\end{array}$ \\
\hline 9. & antennal sensory appendage & longer, $3 \times \mathrm{An} 3 \mathrm{~L}$ & shorter, $2 \times$ An $3 \mathrm{~L}$ \\
\hline 10. & maxillary palp & mp1 elongate; $\mathrm{mp} 3$ longer than $\mathrm{mp} 2$ & $\begin{array}{l}\text { mp1 sub-quadrate; } m p 3 \text { nearly as long as } \\
\text { mp2 }\end{array}$ \\
\hline 11. & $\begin{array}{l}\text { subbasal mesal seta on stipital projec- } \\
\text { tion }\end{array}$ & present & absent \\
\hline 12. & cardo & narrowly fused to submentum & broadly fused to submentum \\
\hline 13. & labial palp & lp2 shorter than $1 \mathrm{p} 1$ & lp2 longer than $1 \mathrm{p} 1$ \\
\hline 14. & dorsal setae on all body segments & more numerous, with papillate insertions & less numerous, with simple insertions \\
\hline 15. & $\begin{array}{l}\text { long lateral setae on thoracic seg- } \\
\text { ments }\end{array}$ & absent & present \\
\hline 16. & prothorax & nearly twice as wide as head & only slightly wider than head \\
\hline 17. & pronotum & $\begin{array}{l}\text { anterior part large, convex, separated from } \\
\text { tergal plate }\end{array}$ & anterior part not separated \\
\hline 18. & $\begin{array}{l}\text { setae on median part of meso- and } \\
\text { metasternum }\end{array}$ & 3 pairs & 2 pairs \\
\hline 19. & $\begin{array}{l}\text { pleural setae on meso- and } \\
\text { metathorax }\end{array}$ & $\begin{array}{l}\text { episternum } 2 \text { setae; mesepimeron asetose; } \\
\text { metepimeron } 1 \text { seta }\end{array}$ & episternum asetose; epimeron 1 seta \\
\hline 20. & abdominal tergal plates & distinct on tergites $1-4$ & indistinct \\
\hline 21. & abdominal tergite 9 & subtrapezoidal, transverse & sub-oval, elongate \\
\hline 22. & $\begin{array}{l}\text { articulation between abdominal } \\
\text { segments } 9-10\end{array}$ & ventrally on sternite 9 & distally on sternite 9 \\
\hline 23. & abdominal tergite 10 & $\begin{array}{l}\text { slightly elongate, weakly narrowing } \\
\text { caudad }\end{array}$ & $\begin{array}{l}\text { strongly elongate, strongly narrowing } \\
\text { caudad }\end{array}$ \\
\hline 24. & setae on abdominal sternite 1 & 1 pair in middle, 2 pairs posterolaterally & 2 pairs in middle, $2-5$ pairs posterolaterally \\
\hline 25. & hooks on anal membrane & present & absent \\
\hline
\end{tabular}

visible in dorsal view, a very large number of setae that are mostly asymmetrically distributed and inserted on distinct papillae. In general body form this larva highly resembles immature Scydmaenus tachyoryctidis (Jeannel \& Paulian, 1944) and S. longicollis (Böving \& Craighead, 1953). However, the newly described larva of Scydmaenus hellwigii (Fig. 56) strikingly differs from the nearly onisciform $S$. tarsatus in having a more cylindrical body, without expanded and demarcated lateral parts on the segments, its setae have simple (i.e., not papillate) insertions and abdominal segment 9 is strongly elongate, not transverse (major differences are listed in Table 1). The subcylindrical body shape resembles that of a cyrtoscydmine species, Stenichnus turbatus Casey (Wheeler \& Pakaluk, 1983), but Scydmaenus hellwigii clearly differs in a number of structures, e.g., medially undivided thoracic tergites (divided in Stenichnus), much denser and asymmetrically distributed setae, anterior parts of epicranial sutures adjacent to posteromedian (and not anteromesal) margins of antennal insertions, the antennomere 3 rudimentary (and not nearly half as long as 2) and the two lobes of maxilla with dense microtrichia (and not a single apical lobe bearing only several robust setae). The larva of Scydmaenus hellwigii shares many more characters with $S$. tarsatus than with any of the known immatures of species of Eutheiini, Cephenniini, Cyrtoscydmini, Mastigini, Leptomastacini or Clidicini. Larvae of S. tarsatus and $S$. hellwigii can be distinguished from all remaining Scydmaeninae by the following set of characters, diagnostic for Scydmaenus: the epicranial sutures reach posteromedian margins of antennal insertions; the presence of epicranial supra-antennal pits and a single pair of stemmata; the anterior margin of epipharynx with a row of subtriangular teeth; the mandibles falciform, without 
additional teeth on the mesal margin; the antennomere 3 rudimentary; the antennal sensory appendage sub-conical and asymmetrical; the maxillae with two lobes; the labium strongly constricted between the mentum and prementum; thoracic tergites undivided along midline; the head, thoracic tergites, laterotergites and abdominal segments except sternite 1 densely setose; thoracic sternites and abdominal sternite 1 largely asetose; and lack of urogomphi.

Scydmaenus is a highly diverse, speciose and cosmopolitan genus divided into about 30 subgenera (Newton \& Franz, 1998); it is even more heterogeneous than Eucon$n u s$, the largest and taxonomically most challenging scydmaenine genus. Jałoszyński et al. (2012) recently demonstrated that adults of $S$. tarsatus and $S$. hellwigii, although externally similar, differ strikingly in the architecture of their cephalic central nervous system; also structures on the metaventrite are clearly different between the nominotypical subgenus of Scydmaenus and Cholerus (Jałoszyński, unpubl. observ.). It is therefore not surprising that the larvae of these species differ significantly.

This study, for the first time, demonstrates that scydmaenine larvae can feed on Collembola. Under laboratory conditions, the larvae of $S$. tarsatus showed no interest in mites and fed only on springtails. Jałoszyński (2012a, b) reports that adults of this species ignore armoured oribatid and uropodine mites, but feed readily on softbodied acaridids and springtails (including Ceratophysella and Tomocerus, accepted also by the larvae) and scavenge various dead arthropods. Although their behaviour or food preferences may have been affected by laboratory conditions and in nature they may prefer other prey, it is clear that both adults and larvae of $S$. tarsatus are capable of capturing and feeding on springtails. Since the mouthparts of adult and immature Scydmaenus show a number of differences, this observation is important for understanding the evolution of morphological adaptations for feeding on a particular kind of prey, characteristic of some Scydmaeninae [e.g., Cephenniini (Schuster, 1966a, b; Schmid, 1988a, b)].

ACKNOWLEDGEMENTS. We are indebted to J. Radwański (Department of Invertebrate Zoology, Institute of Systematics and Evolution of Animals of Polish Acad. Sci., Kraków) for identifying the Collembola and to R. Ruta and L. Borowiec (Department of Biodiversity and Evolutionary Taxonomy, University of Wrocław, Wrocław) for their help with collecting adults of $S$. hellwigii.

\section{REFERENCES}

Bergroth E. 1899: Anisosphaera problematica Töm. = Cephennium, larva [Col.]. Bull. Soc. Entomol. Fr. 1899: 295.

Beutel R.G. \& Molenda R. 1997: Comparative morphology of selected larvae of Staphylinoidea (Coleoptera, Ployphaga) with phylogenetic implications. Zool. Anz. 41: 392-394.

Böving A.G. \& CRAIGHEAD F.C. 1931: An illustrated synopsis of the principal larval forms of the order Coleoptera. Entomol. Americana 11: 1-351.

Brown C. \& Crowson R.A. 1980: Observations on Scydmaenid (Col.) larvae with a tentative key to the main British genera. Entomol. Mon. Mag. 115: 49-59.
De Marzo L. 1983: Osservazioni sulla ovideposizione e sul ciclo larvale in Mastigus pilifer Kraatz (Coleoptera, Scydmaenidae). Entomologica (Bari) 18: 125-136.

De Marzo L. 1984: Morfologia delle larve e pupa in Mastigus pilifer Kraatz (Coleoptera, Scydmaenidae). Entomologica (Bari) 19: 61-74.

Dudich E. 1927: Die Cephennium-Larven und ihre Beziehung zu der Insektenordnung Anisosphaeridia. Entomol. Blätt. 23: $85-87$.

Franz H. 1965: Beitrag zur Bodenfauna der Kanarischen Inseln. Zur Kenntnis der Coleopterenfauna von Tenerife und La Gomera. EOS, Rev. Esp. Entomol. 41: 59-66.

Ganglbauer L. 1899: Die Käfer von Mitteleuropa. Bd. 3, Familienreihe Staphylinoidea, 2 Theil, und Familienreihe Clavicornia. Druck und Verlag Karl Gerold's Sohn, Vienna, $1046 \mathrm{pp}$.

Ghilarov M.S. (ed.) 1964: Key to Soil Dwelling Insect Larvae. Nauka, Moscow, 921 pp. [in Russian].

Grebennikov V.V. \& Newton A.F. 2009: Good-bye Scydmaenidae, or why the ant-like stone beetles should become megadiverse Staphylinidae sensu latissimo (Coleoptera). Eur. J. Entomol. 106: 275-301.

HadLey A. 2010: Combine ZP software, new version. URL: http://www.hadleyweb.pwp.blueyonder.co.uk/CZP/News.htm

IONESCO M.A. 1937: La larve de Cephennium carnicum Rh, Etude morphologique. In: Hommage au Prof. E.C. Teodoresco. Institut de Arte Grafica si Editura "Marvan", Bukarest, pp. 101-109.

JAŁOSZYŃSKI P. 2012a: Adults of European ant-like stone beetles (Coleoptera: Staphylinidae: Scydmaeninae) Scydmaenus tarsatus Müller \& Kunze and S. hellwigii (Herbst) prey on softbodied arthropods. Entomol. Sci. 15: 35-41.

JAŁOSZYŃSKI P. 2012b: Observations on cannibalism and feeding on dead arthropods in Scydmaenus tarsatus (Coleoptera: Staphylinidae: Scydmaeninae). Genus 23: 25-31.

JaŁosZyŃSKi P., HüNefeld F. \& Beutel R.G. 2012: The evolution of "deformed" brains in ant-like stone beetles (Scydmaeninae, Staphylinidae). Arthrop. Struct. Dev. 41: 17-28.

JEANNEL R. 1909: Biospeologica. X. Coléoptères (seconde série). Arch. Zool Exp. Gén. 1: 447-532.

Jeannel R. \& Paulian R. 1945: Mission scientifique de l'Omo, VI (57). Faune des terriers des Rats-Taupes. IV. Coléoptères. Mém. Mus. Natn. Hist. Nat. 19: 1-214.

Kasule F.K. 1966: The subfamilies of the larvae of Staphylinidae (Coleoptera) with keys to the larvae of the British genera of Steninae and Proteininae. Trans. Entomol. Soc. Lond. 118: 261-283.

KILIAN A. 2007: Comparative morphology of larval Camiarinae (Coleoptera: Leiodidae) Part I. Genus Paragyrtodes Szymczakowski, 1966. Zootaxa 1640: 1-39.

KüHnelt W. 1961: Soil Biology. Faber \& Faber, London, 397 pp.

KLAUSNITZER B. 1978: 5.8 Scydmaenidae. In Klausnitzer B. (ed.): Bestimmungsbücher zur Bodenfauna Europas. Lieferung 10. Ordung Coleoptera (Larven). Akademie-Verlag, Berlin, pp. 93-94.

Klausnitzer B. 1997: 20. Familie: Scydmaenidae. In Klausnitzer B. (ed.): Die Larven der Käfer Mitteleuropas. 4. Band. Polyphaga, Teil 3. Goecke \& Evers, Krefeld, and Gustav Fischer Verlag, Jena, Stuttgart, Lübeck, Ulm, pp. 69-82.

LARSSON S.G. 1941: Danske Billelarver, Bestemmelsnogle til Familie. Entomol. Medd. 22: 239-259.

Meinert F. 1888: Scydmaenus-Larven. Entomol. Medd. 1: $144-150$.

Morimoto K \& Hayashi N. 1986: The Coleoptera of Japan in Color. Vol. 1. Hoikusha, Osaka, 320 pp. 
Newton A.F. 1991: Scydmaenidae (Staphylinoidea). In Stehr F.W. (ed.): Immature Insects. Vol. 2. Kendall/Hunt, Dubuque, IA, pp. 330-334.

NeWton A.F. \& Franz H. 1998: World catalog of the genera of Scydmaenidae (Coleoptera). Koleopt. Rundsch. 68: 137-165.

O'KeEFE S.T. 2005: Scydmaenidae Leach, 1815. In Beutel R.G. \& Leschen R.A.B. (eds): Handbook of Zoology. Coleoptera, Beetles. Vol. 1: Morphology and Systematics (Archostemata, Adephaga, Myxophaga, Polyphaga partim). De Gruyter, Berlin, New York, pp. 280-288.

O'Keefe S.T. \& Monteith G.B. 2000: Clidicus abbotensis O'Keefe, a new species of Scydmaenidae (Coleoptera: Staphylinoidea) from Australia with description of the larva. Mem. Queensl. Mus. 46: 211-223.

PaULian R. 1941: Les premiers états des Staphylinoidea (Coleoptera). Étude de morphologie comparée. Mém. Mus. Natn. Hist. Nat. 15: 1-361.

Peyerimhoff P. 1899: Description de la larve de Cephennium laticolle Aub. (Col.). Bull. Soc. Entomol. Fr. 170-174.

ScHMID R. 1988a: Die Larven der Ameisenkäfer (Scydmaenidae, Staphylinoidea) - Neu- und Nachbeschreibung mit einem vorläufigen Bestimmungsschlüssel bis zur Gattung. Mitt. Badisch. Landesv. Naturk. Naturs. 14: 643-660.

Schmid R. 1988b: Morphologische Anpassungen in einem Rauber-Beute-System: Ameisenkafer (Scydmaenidae, Sta- phylinoidea) und gepanzerte Milben (Acari). Zool. Jb. Syst. Ökol. Tiere 115: 207-228.

Scholz R. 1926: Die larve von Cephennium reitteri Bris. (Col.). Entomol. Blätt. 22: 103-104.

SCHUSTER R. 1966a: Über den Beutefang des Ameisenkäfers Cephennium austriacum Reitter. Naturwissenschaften 53: 113.

SchUSteR R. 1966b: Scydmaeniden-Larven als Milbenräuber. Naturwissenschaften 53: 439-440.

Silvestri F. 1899. Prima nota intorno all Anisosphaera Töm. Ann. Mus. Civ. St. Nat. Genova 39: 613-619.

TÖMÖSVARY Ö. 1882: Contributions to our fauna of Thysanura. Matem. Természettud. Közl. 18: 119-131 [in Hungarian].

Vít S. \& De Marzo L. 1989: Description of the larva of Leptomastax hypogeus Pirazzoli (Coleoptera Scydmaenidae). Arch. Sci. 42: 569-578.

WHEELER Q.D. 1990: Morphology and ontogeny of postembryonic larval Agathidium and Anisotoma (Coleoptera: Leiodidae). Am. Mus. Novit. 2986: 1-46.

WheELER Q.D. \& PAKALUK J. 1983: Descriptions of larval Stenichnus (Cyrtoscydmus): S. turbatus and S. conjux, with notes on their natural history (Coleoptera: Scydmaenidae). Proc. Entomol. Soc. Wash. 85: 86-97.

Received February 20, 2012; revised and accepted April 20, 2012 